\title{
Pre-activation of ice-nucleating particles by the pore condensation and freezing mechanism
}

\author{
Robert Wagner, Alexei Kiselev, Ottmar Möhler, Harald Saathoff, and Isabelle Steinke \\ Karlsruhe Institute of Technology (KIT), Institute of Meteorology and Climate Research (IMK-AAF), \\ Hermann-von-Helmholtz-Platz 1, 76344 Eggenstein-Leopoldshafen, Germany \\ Correspondence to: Robert Wagner (robert.wagner2@kit.edu)
}

Received: 7 October 2015 - Published in Atmos. Chem. Phys. Discuss.: 27 October 2015

Revised: 5 February 2016 - Accepted: 8 February 2016 - Published: 23 February 2016

\begin{abstract}
In spite of the resurgence in ice nucleation research a comparatively small number of studies deal with the phenomenon of pre-activation in heterogeneous ice nucleation. Fifty years ago, it was shown that various mineral dust and volcanic ash particles can be pre-activated to become nuclei for ice crystal formation even at temperatures as high as $270-271 \mathrm{~K}$. Pre-activation was achieved under ice-subsaturated conditions without any preceding macroscopic ice growth by just temporarily cooling the particles to temperatures below $228 \mathrm{~K}$. A two-step mechanism involving capillary condensation of supercooled water and subsequent homogeneous freezing was proposed to account for the particles' enhanced ice nucleation ability at high temperatures. This work reinvestigates the efficiency of the proposed preactivation mechanism in temperature-cycling experiments performed in a large cloud chamber with suspended particles. We find the efficiency to be highest for the clay mineral illite as well as for highly porous materials like zeolite and diatomaceous earth, whereas most aerosols generated from desert dust surface samples did not reveal a measurable preactivation ability. The pre-activation efficiency is linked to particle pores in a certain size range. As estimated by model calculations, only pores with diameters between about 5 and $8 \mathrm{~nm}$ contribute to pre-activation under ice-subsaturated conditions. This range is set by a combination of requirements from the negative Kelvin effect for condensation and a critical size of ice embryos for ice nucleation and melting. In contrast to the early study, pre-activation is only observed for temperatures below $260 \mathrm{~K}$. Above that threshold, the particles' improved ice nucleation ability disappears due to the melting of ice in the pores.
\end{abstract}

\section{Introduction}

The microphysical processes leading to the formation of ice particles in the Earth's atmosphere are still poorly understood. As emphasised by the most recent report of the Intergovernmental Panel on Climate Change (Boucher et al., 2013), the accurate parametrisation of such microphysical processes is essential for the reliable simulation of clouds in modern climate models. Only a minor subset of the atmospheric aerosol particles is able to act as ice-nucleating particles (INPs), thereby promoting ice formation at lesser supersaturation or supercooling compared to homogeneous ice nucleation (Hoose and Möhler, 2012; Murray et al., 2012). Amongst this subset, an even smaller fraction of aerosol particles can trigger the glaciation of supercooled cloud droplets at temperatures higher than $258 \mathrm{~K}$. INP measurements for various geographic locations indicate that the INP number concentration typically decreases by 2 orders of magnitude when the temperature increases from 253 to $263 \mathrm{~K}$ (Pruppacher and Klett, 1997). Most of the INPs that are active above $258 \mathrm{~K}$ are supposed to be composed of biological material (Murray et al., 2012; Prenni et al., 2009).

A potential mechanism that can increase the number concentration of INPs at warm temperatures is pre-activation, denoting the enhanced ice nucleation ability of an INP after its exposure to low temperature and/or its prior involvement in an ice nucleation event (Knopf and Koop, 2006; Pruppacher and Klett, 1997; Vali, 2008). In the latter case, it is argued that small pockets of ice can survive in pores or cracks at the particle surface even in an ice-subsaturated environment after the sublimation of the ice cloud from the preceding nucleation event (Mossop, 1956). These ice pockets represent sites where macroscopic ice crystals can easily grow 
again when the INP is again exposed to ice-supersaturated conditions in a succeeding nucleation event. Fifty years ago, it was shown that by a two-step mechanism of pore condensation of supercooled water and subsequent homogeneous freezing, pre-activated INPs with such ice pockets can also be formed in cold and dry air without the prior nucleation of macroscopic ice crystals at high humidity (Higuchi and Fukuta, 1966). These experiments were conducted with the INPs deposited onto a metal foil. As an example, $10 \%$ of kaolin and even close to $100 \%$ of montmorillonite particles were pre-activated to become INPs at $258 \mathrm{~K}$ by temporarily cooling them below $228 \mathrm{~K}$ in an environment that was subsaturated with respect to ice. After further warming above $258 \mathrm{~K}$, the fraction of particles that retained their preactivation decreased due to the melting of ice in the pores (Fukuta, 1966; Higuchi and Fukuta, 1966), but a $0.1 \%$ fraction of pre-activated INPs was still present at temperatures as high as $270-271 \mathrm{~K}$.

For decades, no follow-up studies on the suggested twostep pore condensation and freezing (PCF) mechanism were undertaken. Only 3 years ago, new experiments revealed that crystals of three organic model substances nucleated and grew in a surface cavity via the PCF mechanism from saturated vapour, i.e. without the need for supersaturation in the gas phase (Kovács et al., 2012). Shortly later, it was proposed that many observed ice nucleation events previously ascribed to the deposition ice nucleation mode, which by definition proceeds without prior formation of a liquid (Vali et al., 2015), could also be due to the PCF mechanism (Marcolli, 2014). This suggestion was based on the observation that many INPs reveal a strong increase in their ice nucleation ability just below the homogeneous freezing temperature of supercooled water at $237 \mathrm{~K}$. In cloud chamber experiments at our own laboratory, we have recently unravelled a pre-activation pathway which involves temperature cycling of INPs composed of solid organic and inorganic crystals that have crystallised from aqueous solution droplets (Wagner et al., 2014). Here, residuals of the aqueous solution are trapped within the crystals and can freeze when cooled below their respective homogeneous or heterogeneous freezing temperature. This leads to the formation of ice pockets in the crystalline INPs, which can act as efficient sites for ice growth even at warmer temperatures where the intrinsic heterogeneous ice nucleation ability of the unprocessed INPs is very low. In contrast to the PCF mechanism, however, the origin of the ice pockets in these experiments is residual water enclosed in the crystallised aqueous solution droplets and not the capillary condensation of water vapour on a dry particle surface at a relative humidity $\left(\mathrm{RH}_{\mathrm{w}}\right)$ below water saturation. In view of the resurged interest in the PCF mechanism, we considered it timely to perform a novel experimental study on its efficiency using the large aerosol and cloud chamber facility AIDA (Aerosol Interaction and Dynamics in the Atmosphere), which enables long-term processing of suspended INPs under well-defined temperature and $\mathrm{RH}_{\mathrm{w}}$ conditions and where the modification of the ice nucleation ability of the INPs can be investigated by adiabatic expansion cooling experiments (Wagner et al., 2006).

In this contribution, we report on the results of the first systematic study on the pre-activation of INPs under icesubsaturated conditions since the original work in 1966. As a benchmark, we first tested aerosol particles with a highly porous structure, like zeolite (Janssen et al., 2002) and diatomaceous earth particles (Korunic, 1998), where we expected the efficiency of the PCF mechanism to be highest. We then compared these results to those obtained for atmospherically abundant INPs like mineral dust, volcanic ash, and soot particles. Our paper is organised as follows. Section 2 describes the instrumentation of the AIDA aerosol and cloud chamber and presents the investigated materials. In Sect. 3.1, we introduce the applied experimental procedure and the observed pre-activation phenomenon based on the measurement data for zeolite particles. Thereafter, we summarise the pre-activation efficiency measured for all substances in Sect. 3.2. Detailed measurement data for those substances are given in Appendices A-E. In Sect. 4, we analyse the pre-activation data based on model calculations of the water condensation, freezing, and melting of ice in pores. Section 5 explores the atmospheric implications of our findings and Sect. 6 concludes with a summary.

\section{Methods}

\subsection{Instrumentation}

The AIDA facility consists of a $84.3 \mathrm{~m}^{3}$ sized aluminium chamber that is housed in an isolating containment whose temperature can be controlled between 333 and $183 \mathrm{~K}$ (Möhler et al., 2003; Wagner et al., 2006). A powerful mixing fan placed at the bottom of the chamber was continuously in operation, providing homogeneous conditions in terms of temperature, relative humidity, as well as aerosol and cloud particle number concentrations throughout the chamber volume. The mean AIDA gas temperature was computed from the average of 11 thermocouple sensors arranged vertically at different height levels of the chamber. Water vapour concentrations, transformed into $\mathrm{RH}_{\mathrm{w}}$ and $\mathrm{RH}_{\mathrm{ice}}$ data based on the formulations by Murphy and Koop (2005), were measured in situ by a tunable diode laser spectrometer (Fahey et al., 2014). The number concentrations of the aerosol particles were measured with a condensation particle counter (CPC3010, TSI), and their size distributions recorded by a scanning mobility particle sizer (SMPS, TSI) and an aerodynamic particle spectrometer (APS, TSI). Cloud hydrometeors (supercooled water droplets and ice crystals) were counted and sized with two optical particles counters (type WELAS 2000, Palas, size ranges $0.7-46$ and 5-240 $\mu \mathrm{m}$ ). The uncertainties for the measurement data are estimated to be $\pm 0.3 \mathrm{~K}$ for temperature, $\pm 5 \%$ for $\mathrm{RH}_{\mathrm{ice}}$, and $\pm 20 \%$ for the 


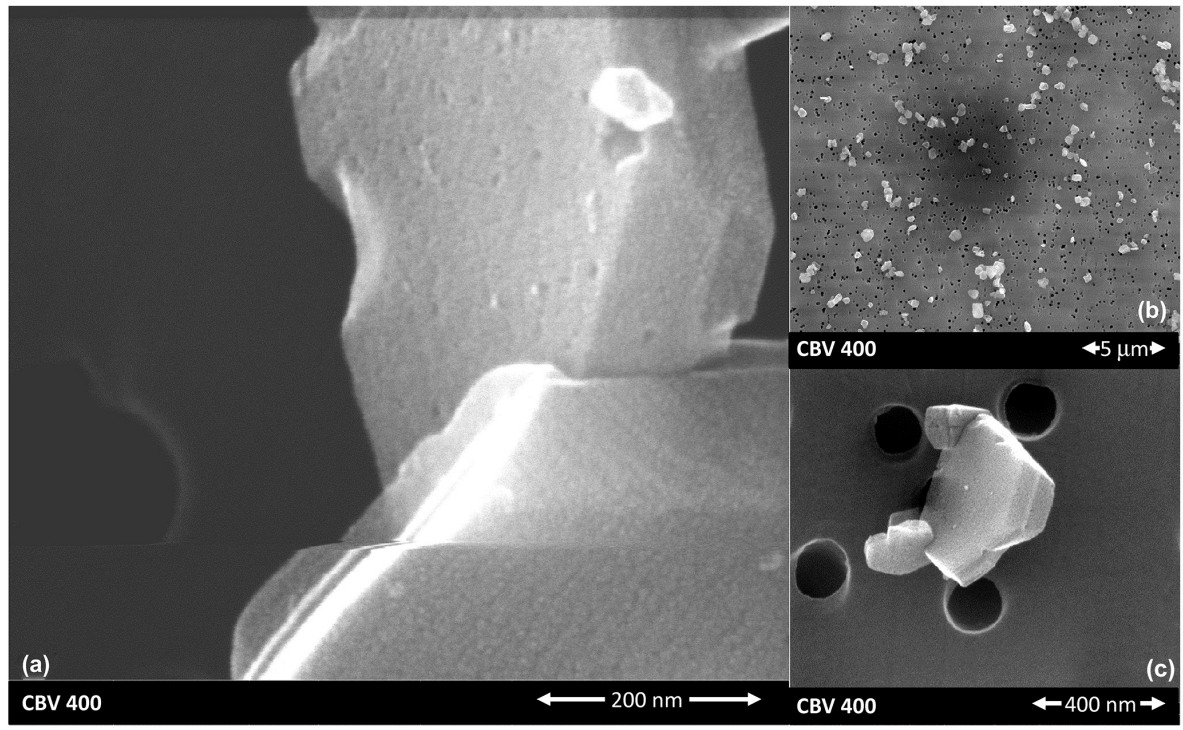

Figure 1. ESEM images of filter-collected zeolite CBV400 particles (a, b, c).

ice particle number concentration. For some experiments, filter samples of the aerosol particles from the AIDA chamber were investigated with an environmental scanning electron microscope (ESEM, FEI Quanta 650 FEG).

\subsection{Materials}

\subsubsection{Reference samples: zeolite and diatomaceous earth particles}

Two types of zeolite powders (trade names CBV100 and CBV400) were purchased from Zeolyst International and used as reference materials to probe the efficiency of the PCF pre-activation mechanism. The samples differ from the dimension of the internal porous network and are therefore suited to investigate the dependence of the pre-activation ability on the pore size. The CBV100 particles are untreated microporous $\mathrm{NaY}$ zeolites with pore diameters in the range between 0.3 and $1.2 \mathrm{~nm}$ (Janssen et al., 2002, 2004). In the CBV400 sample, an artificial mesoporous network was generated by steam treatment of microporous zeolite crystals. The mesopores in the CBV400 particles have a diameter between 4 and $20 \mathrm{~nm}$ (Janssen et al., 2002). For both the CBV100 and CBV400 particles, the homogeneous nucleation of supercooled water and the melting of ice in their cavities have been investigated by differential scanning calorimeter (DSC) measurements (Janssen et al., 2004). We will refer to these findings when analysing the results of our pre-activation experiments.

Diatomaceous earth is a powdered sample of siliceous skeleton remains of diatom algae, with the Bodélé Depression in Northern Africa representing a major natural source for such material (Todd et al., 2007). For our study, we employed a commercially available diatomaceous earth sample
(Agrinova, item 709001) as another reference for particles with a high degree of porosity. Exemplary ESEM images of filter-collected CBV400, CBV100, and diatomaceous earth particles are shown in Figs. 1 and 2. The ensemble image (b) (Fig. 1) reveals that the overall shape of the CBV400 particles is rather compact. A common feature is the occurrence of agglomerated crystals as exemplified in image (c). An indication for the substantial porosity of the particles is their high transparency to the electron beam. In image (c), e.g. one can clearly discern one of the holes of the Nuclepore filter behind the deposited CBV400 crystal. The enlarged image (a) gives an idea of the mesopore system of CBV400, showing numerous open pores at the surface of the particle.

The general habit of the CBV100 particles was observed to be very similar to that of the CBV400 particles. Albeit lacking the larger internal mesoporous network, the CBV100 particles' surface is not completely smooth but reveals a certain degree of roughness due to small cracks and steps. In addition to the microporous network of CBV100, these surface sites as well as void spaces between crystal agglomerates (in Fig. 2d) may also allow for the condensation of supercooled water at $\mathrm{RH}_{\mathrm{W}}<100 \%$ and explain a potential preactivation ability. The two selected ESEM images (e) and (f) of diatomaceous earth (Fig. 2) underline the extremely complex structure of these particles. Apart from large-scale hole patterns, the recordings show clear evidence for smallscale surface roughness and porosity. Our material is similar to another commercial diatomaceous earth sample that was recently probed for its light scattering properties (Alexander et al., 2013). 


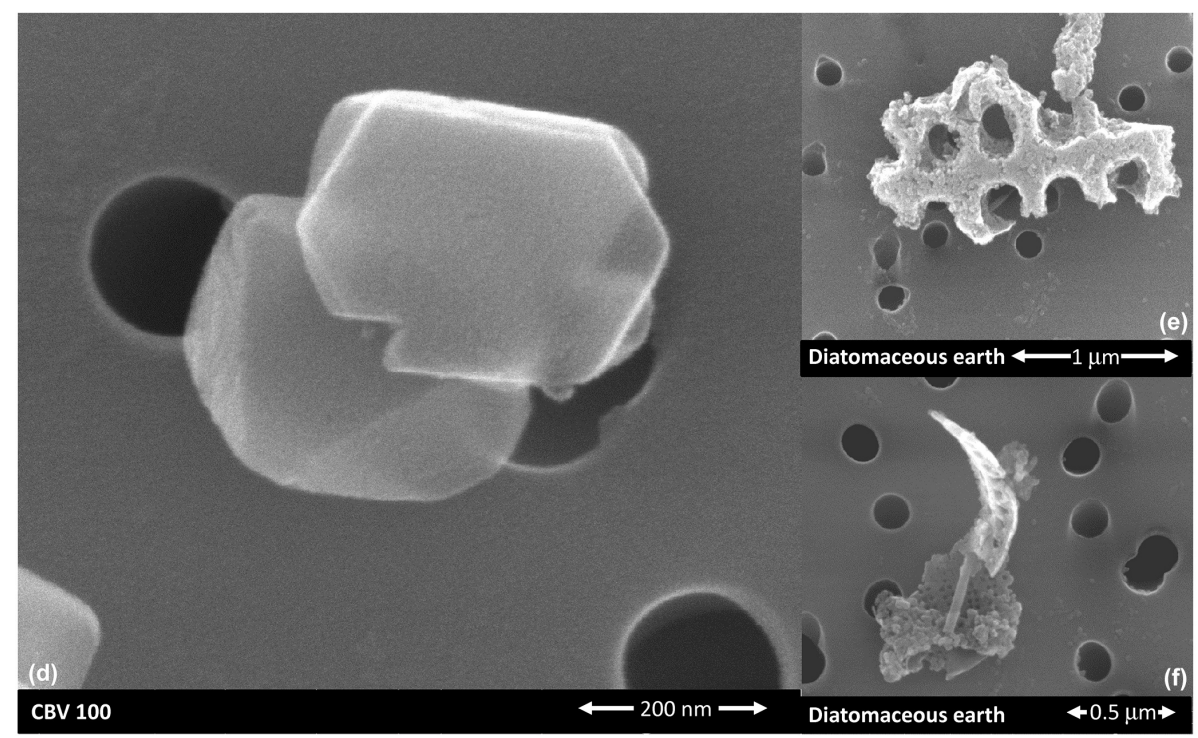

Figure 2. ESEM images of filter-collected zeolite CBV100 (d) and diatomaceous earth particles (e, f).

\subsubsection{Mineral dust, volcanic ash, and soot particles}

In addition to the zeolite and diatomaceous earth particles, we chose six further types of INPs for the pre-activation experiments. The intrinsic heterogeneous ice nucleation abilities of these substances have been characterised in previous AIDA measurement campaigns. The materials include: (i) an Illite NX sample (Arginotec, NX Nanopowder) that was recently distributed as a surrogate for natural desert dusts in a comprehensive laboratory study of ice nucleation measurement techniques (Hiranuma et al., 2015); (ii) a Saharan dust surface sample (SD2) collected about $50 \mathrm{~km}$ north of Cairo, Egypt (Möhler et al., 2006); (iii) an Israeli dust sample (ID) collected from Ramat Hasharon as sediment soil after a dust storm (Kanji et al., 2011); (iv) a Canary Island dust surface sample (CID) collected near the town of Mala on the Island of Lanzarote as a proxy for settled Saharan dust after airborne transport (Kanji et al., 2011; Koehler et al., 2010); (v) a volcanic ash surface sample (EY01) collected $58 \mathrm{~km}$ from the Eyjafjallajökull volcano on Iceland 2 days after a major eruption phase in April 2010 (Steinke et al., 2011); and (vi) Graphite Spark Generator (GSG) soot particles from a commercial graphite spark generator (GfG 1000, Palas) (Möhler et al., 2005).

\subsubsection{Aerosol generation}

The CBV100, CBV400, diatomaceous earth, and Illite NX powders were used as received for aerosol generation. The SD2, ID, CID, and EY01 samples were sieved to obtain the fraction of particles smaller than $75 \mu \mathrm{m}$ in diameter that were then used for aerosol generation. The powder samples were dry-dispersed into the AIDA chamber with a rotating brush generator (RBG 1000, Palas). The RBG was operated with three impactor stages of a five-stage series cyclone system developed at Southern Research Institute (Birmingham, Alabama), yielding a cutoff $\mathrm{d}_{(50)}$ aerodynamic diameter of $1.2 \mu \mathrm{m}$. For injecting the soot particles, the output of the graphite spark generator was directed via two coagulation tubes into the AIDA chamber.

The aerosol particle number concentrations were initially on the order of $10^{3}$ particles $\mathrm{cm}^{-3}$. The recorded number size distributions of the aerosol particles were approximated by unimodal log-normal functions (Hinds, 1999). The fit parameters for the count median diameters, CMD, and the mode widths, $\sigma_{g}$, are summarised in Table 1 . For the soot particles, the CMD value corresponds to the mobility equivalent diameter from the SMPS measurement. For the other compounds, the size spectra from the SMPS and the APS were first combined by converting the mobility and aerodynamic diameters into the volume-equivalent sphere diameter and then fitted by the log-normal function (DeCarlo et al., 2004; Hinds, 1999). For illite NX, SD2, ID, CID, and EY01, the particle density, $\rho_{\mathrm{p}}$, was set to $2.6 \mathrm{~g} \mathrm{~cm}^{-3}$ and the dynamic shape factor, $\chi$, was set to 1.2 . Reduced $\rho_{\mathrm{p}}$ values of 1.9 and $2.3 \mathrm{~g} \mathrm{~cm}^{-3}$ were required to combine the size spectra of the porous zeolite materials CBV400 and CBV100, respectively. The combined size spectrum of the diatomaceous earth particles was obtained with $\rho_{\mathrm{p}}=2.3 \mathrm{~g} \mathrm{~cm}^{-3}$ and $\chi=1.5$.

\subsection{Operation of the AIDA chamber}

Before the start of aerosol injection, the inner walls of the AIDA chamber were partially coated with an ice layer and the vessel was filled with particle-free synthetic air to ambient pressure. The ice-coated walls controlled the prevailing $\mathrm{RH}_{\text {ice }}$ value in the chamber interior to typically $95 \%$. The slightly ice-subsaturated conditions are the result of some in- 
Table 1. Log-normal fit parameters for the number size distributions of the investigated aerosol particles.

\begin{tabular}{lcc}
\hline Material & CMD / $\mu \mathrm{m}$ & $\sigma_{g}$ \\
\hline Zeolite CBV400 & 0.38 & 1.56 \\
Zeolite CBV100 & 0.43 & 1.59 \\
Diatomaceous earth & 0.26 & 1.81 \\
Illite NX & 0.26 & 1.61 \\
Canary Island Dust (CID) & 0.21 & 1.75 \\
Saharan Dust (SD2) & 0.24 & 1.65 \\
Israeli Dust (ID) & 0.25 & 1.61 \\
Icelandic Volcanic Ash (EY01) & 0.26 & 1.54 \\
GSG soot & 0.29 & 1.69 \\
\hline
\end{tabular}

ternal heat sources, causing that the average gas temperature of the chamber is a few tenths of a Kelvin higher than the wall temperature.

After aerosol injection as described in Sect. 2.2.3, the aerosol particles were either immediately probed on their intrinsic heterogeneous ice nucleation ability at a given temperature, or they were probed after overnight temperature cycling to investigate the efficiency of the PCF pre-activation mechanism under ice-subsaturated conditions, as detailed in Sect. 3.1. Temperature adjustments of the AIDA chamber during temperature cycling were usually accomplished at a rate of $5 \mathrm{~K} \mathrm{~h}^{-1}$ during cooling and $2.5 \mathrm{~K} \mathrm{~h}^{-1}$ during warming. To achieve ice formation, supersaturations with respect to ice were induced by expansion cooling, i.e. a controlled reduction of the chamber pressure with a mechanical pump operated at a volume flow rate of typically $2.5 \mathrm{~m}^{3} \mathrm{~min}^{-1}$. This established initial cooling rates for the chamber atmosphere of about $3 \mathrm{~K} \mathrm{~min}^{-1}$. The cooling rates were then steadily decreasing during continued pumping due to the increasing heat flux from the chamber walls, whose temperature remained almost unchanged. For a particular experiment (Sect. 5.3), we used an evacuated, $4 \mathrm{~m}^{3}$ sized aerosol preparation chamber as an additional expansion volume, inducing an almost instantaneous drop of the gas temperature by another $2 \mathrm{~K}$ in the later course of expansion cooling.

\section{Results}

\subsection{The pre-activation phenomenon: detailed measurement data for the CBV400 particles}

Figure $3 \mathrm{a}$ and $\mathrm{b}$ show the intrinsic heterogeneous ice nucleation ability of unprocessed CBV400 crystals that have been dry-dispersed into the AIDA chamber at 251 and $228 \mathrm{~K}$, respectively. After injection, the aerosol particles were subjected to an adiabatic expansion, as performed by a controlled reduction of the chamber pressure (Sect. 2.3). This leads to a decrease in the gas temperature (red lines) and an increase in the relative humidity with respect to ice, $\mathrm{RH}_{\text {ice }}$
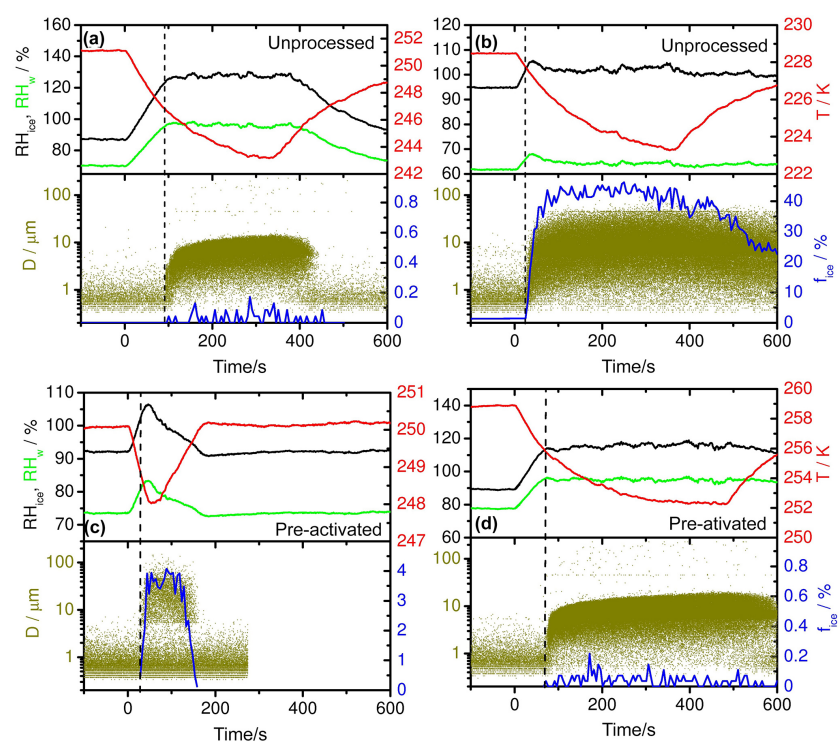

Figure 3. Ice nucleation characteristics of unprocessed $(\mathbf{a}, \mathbf{b})$ and pre-activated (c, d) zeolite particles (CBV400) during expansion cooling. Each part shows the relative humidity with respect to ice (black line) and supercooled water (green line), the chamber gas phase temperature (red line), the aerosol and cloud particle size distribution (dark-yellow dots), and the ice-active fraction of the aerosol population (blue line).

(black lines), and supercooled water, $\mathrm{RH}_{\mathrm{w}}$ (green lines). The expansion run started at $251 \mathrm{~K}$ (Fig. 3a) proved the CBV400 particles to be very inefficient INPs. There was no formation of ice particles via deposition nucleation before water saturation had been exceeded during the expansion, upon which the aerosol particles acted as cloud condensation nuclei and a dense cloud of supercooled water droplets was formed (vertical dashed line). The cloud droplets grew to diameters of about $10 \mu \mathrm{m}$, as inferred from the scattering signals of the optical particle counters (OPCs, dark-yellow dots). Nucleated ice crystals grew to larger diameters than the cloud droplets and can therefore separately be identified in the OPC data sets, enabling the calculation of the ice-active fraction of the aerosol population, $f_{\text {ice }}$ (blue lines). As evident from the OPC data in Fig. 3a, only a tiny fraction of less than $0.1 \%$ of the immersed CBV400 particles is ice-active in the immersion freezing mode in the temperature range of 246 to $243 \mathrm{~K}$. The heterogeneous ice nucleation ability changed profoundly when the CBV400 particles were probed in an expansion run that was started at a temperature below $237 \mathrm{~K}$ (Fig. 3b). Here, almost immediately after the start of expansion cooling at time zero, a dense ice cloud was formed at a $\mathrm{RH}_{\text {ice }}$ threshold of only $102 \%$. More than $40 \%$ of the CBV400 particles acted as INPs even though the peak $\mathrm{RH}_{\text {ice }}$ value during the expansion run never exceeded a value of $105 \%$. It is the sudden appearance of this extraordinarily high ice nucleation ability just below $237 \mathrm{~K}$ which puts in doubt the assignment of this nucleation mode to a deposition nucleation mecha- 
nism, given that there is no a priori reason why this pathway should abruptly be inefficient for temperatures above $237 \mathrm{~K}$ (Marcolli, 2014; Pruppacher and Klett, 1997). More likely, the ice nucleation mode evident in Fig. $3 \mathrm{~b}$ is due to the depositional growth of ice pockets which already form by the PCF mechanism after injecting the CBV particles into the AIDA chamber at $228 \mathrm{~K}$ and $\mathrm{RH}_{\text {ice }}=95 \%$.

As an indirect proof for the PCF mechanism, we performed the following pre-activation experiment. The CBV400 particles were dry-dispersed into the AIDA vessel at $253 \mathrm{~K}$, upon which the chamber was cooled to $228 \mathrm{~K}$ and warmed to $250 \mathrm{~K}$. During temperature cycling, the chamber air remained slightly subsaturated with respect to ice with a typical $\mathrm{RH}_{\text {ice }}$ of $95 \%$ (see Sect. 2.3). No intermediate expansion cooling runs were conducted, meaning that the aerosol particles were not subjected to ice-supersaturated conditions where macroscopic ice crystals could have grown. After warming to $250 \mathrm{~K}$, the zeolite particles were probed for their ice nucleation ability in an expansion cooling run whose data are shown in Fig. 3c. In contrast to the unprocessed CBV400 particles that were almost ice-inactive when probed at the same temperature (Fig. 3a), the pre-activated particles gave rise to a pronounced nucleation mode that formed at a $\mathrm{RH}_{\text {ice }}$ threshold of about $102 \%$. We assign this mode to depositional growth of ice held in the pores of the zeolite particles, which has been formed by the PCF mechanism during temperature cycling. To our knowledge, this is the first demonstration of pre-activation under ice-subsaturated conditions in an experiment with suspended particles. The fraction of ice-active CBV400 particles is about $4 \%$. The macroscopic ice crystals that had formed in the expansion run were then rapidly sublimed by the addition of dry synthetic air, which led to a temporary decrease in $\mathrm{RH}_{\text {ice }}$ to a minimum value of about $90 \%$. As pore ice was shown to be stable even down to much lower $\mathrm{RH}_{\text {ice }}$ values of 40 to $5 \%$ (Knopf and Koop, 2006), the experiment was continued with the same aerosol load to investigate up to which temperature the preactivation behaviour can still be observed, i.e. to determine when the pore ice starts to melt and the improved ice nucleation ability disappears.

For that purpose, the AIDA temperature was stepwise increased by about $3 \mathrm{~K}$ and expansion cooling runs were conducted at the higher temperatures as well. When probed at 253 and $256 \mathrm{~K}$, the CBV400 particles were still ice-active in the depositional growth mode, however with reduced number fractions of only 1.7 and $0.2 \%$ of the particles, respectively. After further warming to $259 \mathrm{~K}$ (Fig. 3d), the depositional growth mode disappeared, and only a small number of ice crystals was formed after the droplet activation of the zeolite particles. Albeit small, the ice-active fraction is still higher compared to the intrinsic ice nucleation ability when the unprocessed CBV400 particles are directly probed at that temperature without temporary cooling. We observed similar behaviour for a variety of compounds (additional examples are discussed in Appendices A-E), which leads us to con- clude that the small ice nucleation mode shown in Fig. 3d is due to pre-activation as well. We tentatively assign it to the condensational growth of residual ice that is deeply captured in pores and cannot grow by water vapour deposition on the timescale of our experiments but only when getting in contact with liquid supercooled water after the droplet activation.

We performed a further pre-activation experiment where the CBV400 particles were again injected at $253 \mathrm{~K}$, cooled to $228 \mathrm{~K}$, but then directly warmed to $259 \mathrm{~K}$ to perform an expansion cooling run at that temperature. We observed a similar nucleation mode due to condensational ice growth after droplet activation as shown in Fig. 3d, underlining that the intermediate expansion runs conducted at 250,253, and $256 \mathrm{~K}$ in the previous experiment did not lead to a loss of pre-activated particles, but that the pre-activation efficiency is actually significantly reduced at $259 \mathrm{~K}$.

\subsection{Summary of the pre-activation behaviour for all substances}

Figure 4 summarises the pre-activation behaviour for the other compounds investigated. For each aerosol type, we applied the same temperature cycling, i.e. injection at $253 \mathrm{~K}$ and temporary cooling to $228 \mathrm{~K}$. The filled bars denote the ice-active fractions of the pre-activated particles in the depositional growth mode at $\mathrm{RH}_{\mathrm{w}}$ below $100 \%$ at various temperatures after warming, and those without colour filling represent the condensational ice growth mode after droplet activation. Partly, both modes were observed successively in a single expansion cooling experiment. This happened when the number concentration of ice crystals formed by depositional growth was so small that the water vapour supersaturation was not efficiently depleted, so that water saturation was exceeded upon continued pumping and the condensational ice growth mode could become active. Additional data from the AIDA experiments are provided in Appendices A-E to support that the ice-active fractions depicted in Fig. 4 are due to pre-activation and not related to the intrinsic heterogeneous ice nucleation ability of the aerosol particles.

Let us first compare the pre-activation behaviour of the mesoporous CBV400 particles with that of the second zeolite sample, namely the microporous CBV100 particles. As the melting temperature of ice is expected to decrease with the pore diameter (Marcolli, 2014), we have performed the initial pre-activation run with the microporous CBV100 particles already at a lower temperature of $246 \mathrm{~K}$ after temperature cycling. Here, $1 \%$ of the pre-activated particles were ice-active in the depositional growth mode (Fig. 4). At $250 \mathrm{~K}$ where the first pre-activation run with the CBV400 particles was conducted, only $0.08 \%$ of the CBV100 particles still showed the depositional ice growth mode, followed by a somewhat larger condensational ice growth mode after droplet activation $\left(f_{\text {ice }}=0.6 \%\right)$. After further warming to $253 \mathrm{~K}$, the preactivation mode has almost disappeared, showing that the pre-activation efficiency of the microporous CBV100 parti- 


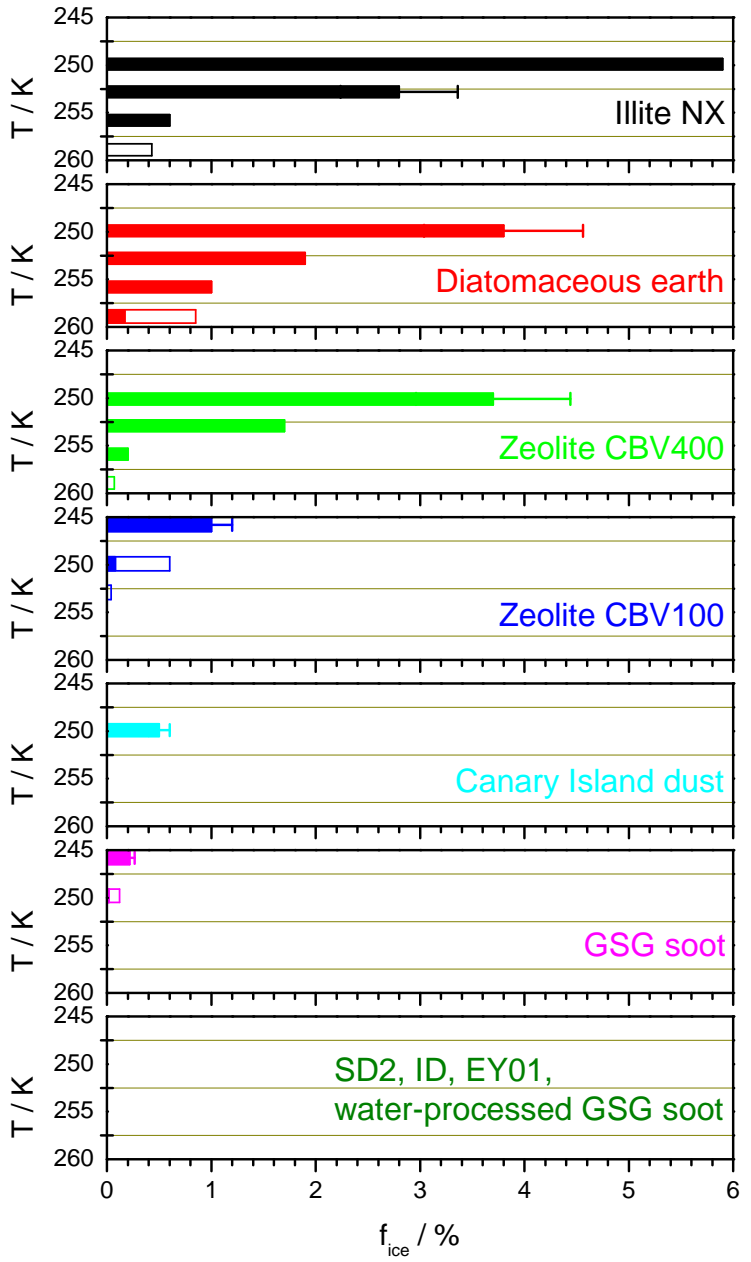

Figure 4. Temperature-dependent ice-active fractions after preactivation for different aerosol types in the depositional ice growth mode (filled bars) and the condensational ice growth mode (bars without colour filling). Exemplary error bars denote the uncertainty of $\pm 20 \%$ for $f_{\text {ice }}$. The estimated detection limit for $f_{\text {ice }}$ is $0.04 \%$. For the SD2, ID, EY01, and water-processed GSG soot particles, the pre-activation efficiency is below this limit.

cles is much smaller compared to the mesoporous CBV400 sample.

Two samples that show a similar pre-activation efficiency as CBV400 are diatomaceous earth and illite NX. Amongst the CBV400, illite NX, and diatomaceous earth samples, the illite NX particles show the highest ice-active fraction of almost $6 \%$ for pre-activation at a temperature of $250 \mathrm{~K}$ (Fig. 4). The diatomaceous earth particles feature the most dominant retention of the pre-activation behaviour at warmer temperatures, being the only sample where even after warming to $259 \mathrm{~K}$ a small depositional ice growth mode could still be observed. Amongst the four natural dust and volcanic ash samples, only the CID particles showed a small pre-activation mode at $250 \mathrm{~K}$ with $f_{\text {ice }}=0.5 \%$ in the depositional growth mode (Fig. 4). For SD2, ID, and EY01, the heterogeneous ice nucleation ability was not enhanced after temperature cycling. A small pre-activation ability was measured for the GSG soot particles at temperatures up to $250 \mathrm{~K}$. This pre-activation behaviour was only observed when the freshly emitted, fractal-like soot agglomerates were immediately subjected to the temperature cycling program. In a second type of experiment, the soot particles were first processed by a droplet activation run at $253 \mathrm{~K}$ before cooling them to $228 \mathrm{~K}$. Water condensation and evaporation leads to restructuring and collapsing of the soot aggregates (Ma et al., 2013). For these water-processed GSG soot particles, the pre-activation ability disappeared.

\section{Discussion}

\subsection{Theoretical considerations on the water condensation, freezing, and melting of ice in pores}

Figure 5a shows the time series of the AIDA temperature during a typical pre-activation experiment. We have used a colour coding to discriminate between the three individual processes that have to be considered for the interpretation of the observed pre-activation behaviour. Process I (red-hatched area) is the capillary condensation of supercooled water when the AIDA chamber is cooled from $253 \mathrm{~K}$ (starting temperature for aerosol injection, point A) to $237 \mathrm{~K}$ (homogeneous freezing temperature of supercooled water, point B). Process II (yellow-hatched area) is the freezing of capillary-held water when the AIDA temperature is further reduced from 237 to $228 \mathrm{~K}$ (point C). Finally, process III (green-hatched area) is the melting of ice in the capillaries when again increasing the temperature of the AIDA chamber. The humidity and temperature conditions for the occurrence of these processes depend on the pore diameter. Process I is quantitatively analysed based on the negative Kelvin equation that determines the onset of capillary condensation as a function of the pore size (Fig. 5b). This sets a maximum pore dimension for which condensation is just possible at the prevailing $\mathrm{RH}_{\mathrm{w}}$ in the AIDA chamber. Process II is analysed based on the temperature-dependent pore ice stability curve (Fig. 5c), which is derived from the critical embryo size for homogeneous ice nucleation as defined in Classical Nucleation Theory. This sets a minimum pore dimension for which freezing of the liquid is possible at the given AIDA temperature. The same curve (Fig. 5c) applies for process III, the melting of ice in the pores. This analysis yields the maximum temperature for which the pre-activation ability by the PCF mechanism can still be observed in the AIDA chamber. In the following three sections, we outline the details of our calculations. 

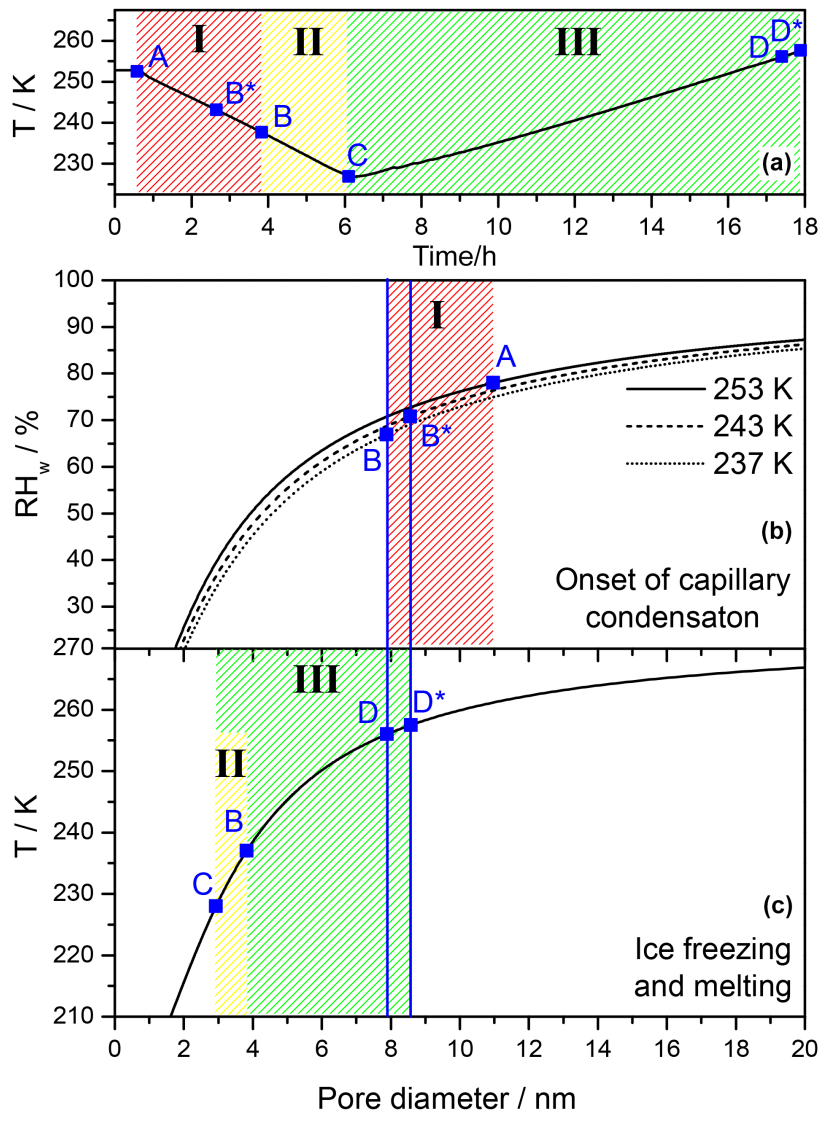

Figure 5. (a) Exemplary time series of the AIDA wall temperature for a pre-activation experiment with diatomaceous earth particles. The three different stages of the experiment are (I) the capillary condensation of supercooled water (red-hatched area), (II) the freezing of capillary-held water (yellow-hatched area), and (III) the melting of ice in the capillaries (green-hatched area). Specific time marks of the experiment (blue squares) are explained in the text. Process I is analysed in terms of the pore-size-dependent onset $\mathrm{RH}_{\mathrm{W}}$ of capillary condensation (b), whereas processes II and III are controlled by the ice freezing and melting temperatures (c). The pore condensation curves (b) were computed with the negative Kelvin equation (Eq. 1) for 253, 243, and $237 \mathrm{~K}$. The temperature-dependent pore ice stability curve (c) is derived from the critical embryo size for homogeneous ice nucleation as defined in Classical Nucleation Theory (Eq. 2). Ice in pores is assumed to be stable only at pore diameters and temperatures below this line. See Sect. 4.1 for computational details.

\subsubsection{Process I: capillary condensation of supercooled water}

The concavity of the water surface in a pore results in a Kelvin effect that is inverse compared to a convex liquid droplet, meaning that water condensation can already occur at $\mathrm{RH}_{\mathrm{w}}<100 \%$ (Sjogren et al., 2007). Quantitatively, this is taken into account by adding a minus sign to the argument of the exponential of the Kelvin equation:

$$
\frac{e_{\mathrm{w}}}{e_{\mathrm{sat}, \mathrm{w}}}=\exp \left(-\frac{2 M_{\mathrm{w}} \sigma_{\mathrm{w} / a}}{R T \rho_{\mathrm{w}} a}\right) \text {. }
$$

Equation (1) describes the reduction of the saturation water vapour pressure over a concave water meniscus, $e_{\mathrm{w}}$, in relation to that over a flat water surface, $e_{\mathrm{sat}, \mathrm{w}}$ (Pruppacher and Klett, 1997). The quotient $e_{\mathrm{w}} / e_{\mathrm{sat}, \mathrm{w}}$ equals the saturation ratio of moist air with respect to a plane water surface. $M_{\mathrm{w}}$ is the molecular weight of water, $\sigma_{\mathrm{w} / a}$ the surface tension for a water/humid-air interface, $R$ the universal gas constant, $\rho_{\mathrm{w}}$ the density of water, $T$ the absolute temperature, and $a$ the radius of curvature of the water surface in a capillary. For a circular capillary, $a$ is equal to $D /(2 \cos \Theta)$, where $D$ is the pore diameter and $\Theta$ the contact angle between water and the pore wall (Fukuta, 1966). In the case of fully wettable capillaries with a zero contact angle, the radius of curvature is equal to the pore radius.

As shown by Marcolli (2014), the measured onset relative humidities for the capillary condensation of water in pores of different mesoporous materials can adequately be described by Eq. (1). We have therefore used this equation to calculate the $\mathrm{RH}_{\mathrm{w}}$ values for the onset of capillary condensation of supercooled water for three relevant temperatures to predict the upper size limit of pores that can fill with water at the $\mathrm{RH}_{\mathrm{w}}$ conditions prevalent in the AIDA chamber (Fig. 5b). We took into account temperature-dependent parametrisations for $\sigma_{\mathrm{w} / a}$ and $\rho_{\mathrm{w}}$ given by Pruppacher and Klett (1997), but ignored the Tolman correction for the size dependence of surface tension (Rao and McMurry, 1990) and assumed a zero contact angle.

Point A in Fig. 5b represents the starting point of the experimental trajectory, denoting the prevalent value of $\mathrm{RH}_{\mathrm{w}}$ when the aerosol particles were injected into the chamber at a temperature of $253 \mathrm{~K}$ (corresponding to $\mathrm{RH}_{\text {ice }}=95 \%$ at the same temperature). Here, the maximum diameter of fully wettable pores that can fill with water is about $11 \mathrm{~nm}$. When the AIDA chamber is cooled at constant $\mathrm{RH}_{\text {ice }}$ of $95 \%$ to the homogeneous freezing temperature of supercooled water at $237 \mathrm{~K}$ (point B), the relative humidity with respect to supercooled water decreases, meaning that water in larger pores evaporates before it can freeze. When approaching $237 \mathrm{~K}$, capillary-held supercooled water will only be retained in pores with diameters smaller than about $8 \mathrm{~nm}$. Homogeneous freezing could then lead to the formation of ice in such sized pores. Ice formation could also involve slightly larger pores, but this would require that the capillary-held water already freezes heterogeneously at a temperature higher than $237 \mathrm{~K}$ (e.g. at point $\mathrm{B}^{*}$ with $T=243 \mathrm{~K}$ ). We will further discuss this issue in Sect. 4.1.3.

\subsubsection{Process II: freezing of capillary-held water}

In the next step, we analyse the freezing of the capillary-held water when the AIDA temperature is lowered from the ho- 
mogeneous freezing limit (point $\mathrm{B}, 237 \mathrm{~K}$ ) to the minimum temperature of $228 \mathrm{~K}$ (point C). In particular, it has to be examined whether the homogeneous (or heterogeneous) freezing of supercooled water is not impeded for narrow pore diameters. Marcolli (2014) has adopted a quantity from Classical Nucleation Theory to describe the freezing and melting of ice in pores, namely the critical embryo size for homogeneous ice nucleation in the pores. Only if the pore dimension exceeds the critical embryo size, does the ice embryo have a higher tendency to grow, which reduces the free energy of the system, than to shrink, which increases the free energy (Pruppacher and Klett, 1997). Ice formation should therefore be inhibited in pores where an ice embryo cannot grow beyond the critical embryo size, even if the temperature is below $237 \mathrm{~K}$.

The critical radius of a spherical ice embryo for homogeneous ice nucleation, $r_{\mathrm{c}}$, for which the Gibbs free energy of embryo formation within the liquid phase has its maximum, is given by (Murray et al., 2012)

$r_{\mathrm{c}}=\frac{2 M_{\mathrm{w}} \sigma_{\mathrm{i} / \mathrm{w}}}{R T \rho_{\mathrm{i}} \ln \frac{e_{\text {sat, } \mathrm{w}}}{e_{\mathrm{sat}, \mathrm{i}}}}$.

In Eq. (2), $\sigma_{\mathrm{i} / \mathrm{w}}$ is the interfacial tension between water and the ice embryo, $\rho_{\mathrm{i}}$ the density of ice, and $e_{\mathrm{sat}, \mathrm{i}}$ the saturation water vapour pressure over a flat ice surface. Using Eq. (2), we have calculated the temperature-dependent pore diameters needed to incorporate a critical ice embryo as $2 r_{\mathrm{c}}+2 t$, where $t$ accounts for a non-freezing quasi-liquid layer between pore wall and ice embryo (Marcolli, 2014). In this computation, $t$ was set to $0.6 \mathrm{~nm}$ (Marcolli, 2014), temperature-dependent $\rho_{\mathrm{i}}$ values were obtained from the parametrisation given by Pruppacher and Klett (1997), $e_{\text {sat, w }}$ and $e_{\text {sat,i }}$ were calculated according to the formulations by Murphy and Koop (2005), and $\sigma_{\mathrm{i} / \mathrm{w}}$ was taken from the fit of measured homogeneous ice nucleation rate coefficients presented by Zobrist et al. (2007).

The result of the computation is shown in Fig. 5c. Regarding our pre-activation experiments, this curve defines the lower threshold size of pores where ice formation due to freezing of capillary-held water can occur at a given temperature. The yellow-hatched area defines the temperature range of process II as defined in Fig. 5a. At $237 \mathrm{~K}$ (point B), the minimum pore size threshold for freezing of the liquid is about $4 \mathrm{~nm}$, and it further decreases to about $3 \mathrm{~nm}$ at $228 \mathrm{~K}$, the minimum temperature during the experiment (point $\mathrm{C}$ ). Here, all aerosol particles with pores in the diameter range from 3 to $8 \mathrm{~nm}$ therefore have the chance to incorporate ice due to the PCF mechanism even in an ice-subsaturated environment. $3 \mathrm{~nm}$ is the minimum pore size in which capillaryheld water can freeze, and $8 \mathrm{~nm}$ is the maximum pore size in which condensation of supercooled water has been possible. These ice pockets can trigger the depositional ice growth mode when the aerosol particles are directly probed in an expansion cooling experiment started at $228 \mathrm{~K}$. In our pre- activation experiments, however, we want to investigate the survival of such ice pockets and their contribution to depositional ice growth at warmer temperatures. Therefore, we have to consider as the third important process the melting of ice when increasing the temperature in the pre-activation experiments (process III, green-hatched areas in Fig. 5a and c).

\subsubsection{Process III: melting of ice in pores}

For describing the temperature dependence of the melting of ice in pores, the same curve as for the freezing of ice applies (Marcolli, 2014). Once the diameter of a certain pore gets smaller than the critical embryo size during warming, the ice in the pore should melt because shrinkage of the ice phase would lead to a decrease in the free energy of the system. Point D at 257 K (Fig. 5c) therefore denotes the melting temperature of ice in the largest pores in which ice pockets could have been formed via the PCF mechanism in the case of homogeneous freezing at point $\mathrm{B}$. Above that temperature, the pre-activation behaviour should disappear. In the case of heterogeneous freezing at point $\mathrm{B}^{*}$, the temperature threshold for the disappearance of the pre-activation ability could be a few degrees higher (point $\mathrm{D}^{*}$ ), because ice in larger pores with a higher melting temperature were present. The suggestion of heterogeneous freezing is, however, somewhat speculative because repeatedly a non-freezing layer of bound water next to the pore walls was found. Therefore, it remains unclear whether the material of the pore wall can actually trigger the freezing of the free water in the pore space. Marcolli (2014) summarises several studies where freezing and melting of ice were insensitive to variations of the surface properties of the pore walls. However, heterogeneous freezing could explain some of our observations, as discussed in Sect. 4.2.

Whereas heterogeneous freezing would increase the temperature threshold for the loss of the pre-activation ability, the opposite behaviour would be encountered if the capillaries of the porous materials were only partially wettable. Here, the factor $\cos \Theta$ would be less than unity, meaning that the radius of curvature of the water meniscus would be larger than the pore radius, thereby reducing the Kelvin effect. The maximum pore size for water condensation would diminish, and hence the upper threshold temperature for the disappearance of the pre-activation behaviour would decrease.

Accurate values for the contact angles between water and the pore walls of our investigated particles are not available. Rather low $\Theta$ values of equal to or less than $30^{\circ}$ were found for several clay minerals (Janczuk and Bialopiotrowicz, 1988). In order to estimate the effect of a non-zero contact angle, we have redone our calculations for a contact angle of $30^{\circ}$. This reduces the $8 \mathrm{~nm}$ size threshold for capillary condensation at $237 \mathrm{~K}$ to about $6.8 \mathrm{~nm}$, yielding $253 \mathrm{~K}$ instead of $257 \mathrm{~K}$ as the upper temperature for the loss of preactivation. 


\subsection{Application of the model calculations to the observed pre-activation behaviour}

How do the theoretical considerations from Sect. 4.1 apply to our experimental findings from Fig. 4? In good agreement with theory, pre-activation, if observed, is only retained for temperatures below $260 \mathrm{~K}$. Let us consider e.g. the mesoporous zeolite CBV400 particles that have a broad range of pore diameters up to $20 \mathrm{~nm}$. For a pore size of $20 \mathrm{~nm}$, the predicted pore ice melting temperature is about $267 \mathrm{~K}$ (Fig. 5c). In previous experiments where the CBV400 particles were probed in a suspension and water could penetrate in all pores regardless of their size, the maximum of the endothermic peak in the DSC heating scan corresponding to the melting of ice in the mesopores was indeed observed above $260 \mathrm{~K}$ (Janssen et al., 2004). In an ice-subsaturated environment, however, water condensation and subsequent homogeneous freezing is limited to pores with diameters smaller than $8 \mathrm{~nm}$ (point B in Fig. 5b). In good accordance with the expected upper ice melting temperature indicated by point $\mathrm{D}$ in Fig. 5c, the improved ice nucleation ability for the CBV400 particles in the pre-activation experiment is therefore already significantly reduced after raising the temperature from 253 to $256 \mathrm{~K}$, and the last small pre-activation mode is observed at $259 \mathrm{~K}$. The compound that shows the highest pre-activation efficiency after warming to $259 \mathrm{~K}$ is diatomaceous earth. In contrast to the CBV400 particles which do not possess any pronounced intrinsic heterogeneous ice nucleation ability above $237 \mathrm{~K}$, the unprocessed diatomaceous earth particles showed a very strong immersion freezing mode at about $240 \mathrm{~K}$ (see Fig. C1). This heterogeneous ice nucleation mode, if mediated by the non-freezing layer of bound water next to the pore walls, could increase the freezing temperature of the capillary-held water during preactivation (freezing at point $\mathrm{B}^{*}$ instead of B), and thereby increase the upper melting temperature of ice in the pores (melting at point $\mathrm{D}^{*}$ instead of $\mathrm{D}$ ).

Regarding the microporous CBV100 material, the previous experiments where the CBV100 particles were probed in a suspension did not reveal any freezing peaks of pore water down to a temperature of $213 \mathrm{~K}$ (Janssen et al., 2004). Due to the smaller pore sizes of at most $1.2 \mathrm{~nm}$ compared to the mesoporous CBV400 particles, freezing of capillary-held water in CBV100 is inhibited for temperatures above $213 \mathrm{~K}$ (Fig. 5c). How can we then explain the small pre-activation ability observed for CBV100 (Fig. 4) although the minimum temperature during our experiment was only $228 \mathrm{~K}$ ? As preactivation cannot be ascribed to ice formation in the internal microporous network of CBV100, it must be related to other, larger-scaled surface characteristics like cracks, steps, or empty spaces between aggregate particles which could also enable the PCF mechanism (see Sect. 2.1.1). Also in the case of clay minerals like illite, the respective sites for pore condensation and freezing are void spaces arising from the interleaving of plates in the aggregate particle (Aylmore and Quirk, 1967). For soot particles, capillary condensation most likely occurs in the empty spaces between aggregate primary particles (Marcolli, 2014). The compaction of soot aggregates during droplet activation therefore destroys their pre-activation ability. The pre-activation mode of the fractal GSG soot particles already disappeared above $250 \mathrm{~K}$, i.e. at a temperature somewhat lower than observed for the CBV400, diatomaceous earth, and illite NX particles. This might be due to the fact that water contact angles on soot surfaces tend to be higher than for mineral surfaces (Persiantseva et al., 2004), thereby lowering the temperature threshold for the loss of the pre-activation behaviour (see Sect. 4.1.3).

Electron micrographs of the employed natural dust and volcanic ash samples showed particles with irregularities in the surface and partly aggregate-like structure (Linke et al., 2006; Steinke et al., 2011), i.e. prerequisites for making these materials prone to the PCF pre-activation mechanism as well. However, pre-activation by the depositional ice growth mode at temperatures between 245 and $260 \mathrm{~K}$ requires the availability of pores with diameters between about 5 and $8 \mathrm{~nm}$ (Fig. 5c). Apparently, most of the investigated natural dust and volcanic ash particles do not contain pores in this particular size regime due to the absence of pre-activation. The intrinsic heterogeneous ice nucleation ability of a certain compound at $228 \mathrm{~K}$ is a useful indicator to assess its potential pre-activation ability after temperature cycling. Amongst the SD2, ID, CID, and EY01 samples, all particles revealed a heterogeneous ice freezing mode below water saturation when injected and probed in an expansion run started around $228 \mathrm{~K}$ (Fig. E1). Only for the CID particles, however, was the onset of ice formation close to ice saturation as observed for the CBV400 particles (Fig. 3b). This indicates that icefilled pores were already formed by the PCF mechanism at $\mathrm{RH}_{\text {ice }}<100 \%$ before the start of the expansion run, which is the prerequisite for observing pre-activation under icesubsaturated conditions. For the other compounds, a distinct supersaturation threshold was needed to induce ice formation, indicating that there were initially no ice-filled pores available where ice crystals could immediately grow after exceeding $100 \% \mathrm{RH}_{\text {ice }}$ upon expansion cooling. Consequently, these compounds did not reveal any pre-activation behaviour after temperature cycling under ice-subsaturated conditions.

Even for the compounds where pre-activation was detected, only a small percentage of the overall aerosol population acted as pre-activated INPs between 245 and $260 \mathrm{~K}$, showing that only a subset of the particles contained pores in the narrow range of appropriate diameters. The maximum of the differential pore-size distribution for an illite sample, for example, was located at plate separations between 2 and $4 \mathrm{~nm}$ whereas pores larger than $5 \mathrm{~nm}$ were much less frequent (Aylmore and Quirk, 1967). Smaller ice-filled pores can contribute to the dominant depositional ice growth mode observed for illite NX particles at $T<237 \mathrm{~K}$ (Fig. B1, $f_{\text {ice }}=58 \%$ ), but only those larger than $5 \mathrm{~nm}$ are responsible for pre-activation at $250 \mathrm{~K}\left(f_{\text {ice }}=6 \%\right)$. In an earlier study by 
Higuchi and Fukuta (1966), much higher number fractions of the investigated particles were found to retain their preactivation ability upon warming, even at temperatures above $260 \mathrm{~K}$ where in the present study the improved ice nucleation ability had completely disappeared. We currently cannot give an explanation for this difference.

\section{Atmospheric implications}

\subsection{Mechanism of heterogeneous ice nucleation at $T<237 \mathrm{~K}$}

Apart from the impact on heterogeneous ice formation above $237 \mathrm{~K}$, our results provide new insights into the microphysics of the ice nucleation mechanism at lower temperatures. The temperature cycling experiments prove that the pores of certain compounds like illite NX, CBV400, and diatomaceous earth can fill with ice at $\mathrm{RH}_{\text {ice }}<100 \%$ and $T<237 \mathrm{~K}$. Cloud ice crystals can then easily form on the pre-activated particles by depositional ice growth at $\mathrm{RH}_{\text {ice }}>100 \%$ without any activation threshold or specific nucleation site as needed for the actual deposition nucleation process. For compounds that do not have ice-filled pores at ice-subsaturated conditions like SD2 and ID, it remains unclear whether ice formation at higher supersaturation thresholds is due to the PCF mechanism or "true" deposition nucleation without the participation of a liquid phase. An important factor may be the timescale of pore condensation in an uplifting air parcel, i.e. whether this process occurs instantaneously once the threshold relative humidity for a given pore size is surpassed or whether it proceeds more slowly and makes the contribution of the PCF mechanism to ice nucleation less probable. In this regard, it would be important to investigate whether other extensively used INP counters like continuous flow diffusion chambers (CFDCs), which only have particle residence times of the order of a few seconds, would detect the same high ice nucleation efficiency for e.g. unprocessed CBV400 particles at $T<237 \mathrm{~K}$ as inferred from the AIDA, where the aerosol particles reside at least for several minutes before the expansion run is started. In any case, the kinetics of the PCF mechanism needs to be studied in greater detail.

\subsection{Heterogeneous ice nucleation at $T>237 \mathrm{~K}$}

Based on the pre-activation efficiencies shown in Fig. 4, it seems unlikely that the PCF mechanism under icesubsaturated conditions provides a substantial number of additional INPs at very high temperatures above $258 \mathrm{~K}$. In agreement with theoretical considerations on the pore-sizedependent thresholds for water condensation and ice melting, only narrow pores with ice melting temperatures below $260 \mathrm{~K}$ can contribute to pre-activation after temperature cycling at $\mathrm{RH}_{\text {ice }}<100 \%$. This is different from the previously detected pre-activation mechanism for crystallised aqueous solution droplets (Wagner et al., 2014). In that case, larger sized frozen solution pockets can remain encapsulated in the effloresced particles and survive up to the eutectic melting temperature, which for low-soluble compounds like dicarboxylic acids is close to $273 \mathrm{~K}$ (Wagner et al., 2014).

The PCF pre-activation mechanism, however, can increase the efficiency of INPs at moderately high temperatures between 245 and $258 \mathrm{~K}$ where most unprocessed INPs only promote ice formation via immersion freezing above water saturation (DeMott et al., 2011). In contrast, pre-activation allows for depositional ice growth at a much lower ice supersaturation threshold. We identify three key issues for future experimental studies to elaborate the atmospheric importance of this process:

i. Focus on natural dust samples from the Bodélé Depression, consisting of fragments of diatomite sediments. Based on the outcome of our temperature cycling experiments with diatomaceous earth, we expect such dust samples to show a much higher pre-activation efficiency than those probed in the present study (ID1, SD2, and CID).

ii. Coating experiments with inorganic (sulphate, nitrate) and organic material. Will atmospherically relevant coating thicknesses reduce or even completely inhibit the pre-activation ability?

iii. Variation of the relative humidity. Up to which lower $\mathrm{RH}_{\text {ice }}$ threshold pore ice will be stable (Knopf and Koop, 2006)?

In principle, the PCF pre-activation mechanism does not necessitate prior involvement in an ice nucleation event. Unlike in the laboratory where temperature cycling of aerosol particles without the formation of ice crystals can easily be performed, a preceding ice nucleation event might be necessary in the atmosphere to enable the transport of preactivated aerosol particles to lower altitudes (Knopf and Koop, 2006; Roberts and Hallett, 1968). In other words, preactivated particles with ice-filled pores may first contribute to high-altitude cirrus formation by the depositional ice growth mode. Larger ice crystals then fall out by sedimentation and release the pre-activated particles at lower altitudes after the sublimation of the ice crystals, but conserving the ice-filled pores.

Such cycling process was also proposed for the wellestablished pre-activation mechanism where INPs are involved in succeeding ice nucleation events (Roberts and Hallett, 1968), and it was suggested that pre-activation should be considered when modelling the long-range transport of INPs and their impact on cloud formation (Knopf and Koop, 2006). In a study on the atmospheric cycling of oxalic acid aerosol particles (Zobrist et al., 2006), it was stated that there was no suitable method to estimate which percentage of cirrus clouds in the atmosphere has previously undergone ice formation. To our knowledge, such modelling effort to es- 
timate how often pre-activation occurs and affects the overall ice particle number concentrations has not yet been attempted. Given the lack of quantitative model simulations on the contribution of pre-activation to ice cloud formation, we encourage studies to quantify the number concentration of pre-activated particles in atmospheric air masses by in situ measurements. In situ detection of pre-activated INPs by e.g. airborne CFDC instruments requires an inlet tube with the temperature kept at ambient conditions so that ice in the pores cannot melt prior to the actual measurement. At present, we are not aware of such studies in the literature.

\subsection{Pre-activation in a deep convective cloud system}

Another potential pathway for altitude and thereby temperature cycling of atmospheric aerosol particles which is of relevance for pre-activation includes deep convective clouds (Adler et al., 2013). In such a cloud system, the aerosol particles are first activated to cloud droplets at warm temperatures. The cloud droplets can freeze when the temperature drops below the homogeneous freezing temperature of supercooled water, and the cloud-processed aerosol particles are released in ice-subsaturated areas in the outflow of deep convection (Adler et al., 2013). In contrast to the PCF preactivation mechanism at $\mathrm{RH}_{\text {ice }}<100 \%$, droplet activation enables all pores of $\mathrm{CCN}$ active particles to be filled with water, regardless of their size. After homogeneous freezing and sublimation of the ice crystals, ice-filled pores with diameters larger than $8 \mathrm{~nm}$ and a concomitantly higher ice melting temperature should be conserved. We have simulated such cycling in deep convective clouds with zeolite CBV400 particles in the AIDA (Fig. 6a). For that purpose, an expansion cooling run with freshly injected CBV400 particles was started at $242 \mathrm{~K}$. After about $4 \mathrm{~K}$ of cooling, the relative humidity has exceeded water saturation and the seed aerosol particles were activated to a cloud of supercooled water droplets (first vertical line). Only a small number fraction of the zeolite particles thereafter acted as immersion freezing ice nuclei. After further cooling by about $1 \mathrm{~K}$, the gas temperature had approached the homogeneous freezing temperature of supercooled water (second vertical line). At that instance, a valve to an evacuated chamber of $4 \mathrm{~m}^{3}$ volume was opened (see Sect. 2.3). The additional expansion led to a rapid decrease of the gas temperature by another $2 \mathrm{~K}$, causing the entire droplet cloud to glaciate. Afterwards, the ice crystals were sublimed by the addition of dry synthetic air and the AIDA chamber was warmed to $250 \mathrm{~K}$ and above to quantify the enhanced ice nucleation ability of the pre-activated, cloud-processed CBV400 particles.

In Fig. 6b, we compare the temperature-dependent iceactive fractions of CBV400 after PCF pre-activation by temperature cycling with those after cloud-processing, comprising droplet activation, freezing, and sublimation. The latter mechanism profoundly increases the pre-activation efficiency, suggesting that pores can more easily fill with wa-
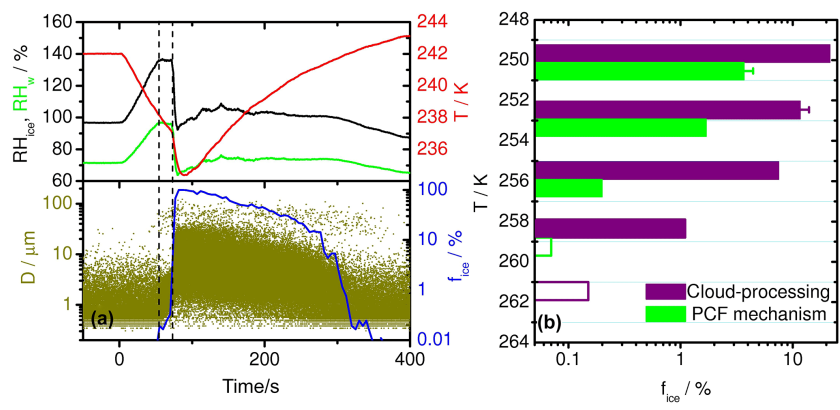

Figure 6. (a) AIDA expansion experiment with zeolite particles (CBV400), simulating aerosol-processing in deep convective clouds. The data types are the same as shown in Fig. 3. (b) Temperature-dependent ice-active fractions for CBV400 particles after pre-activation by the PCF mechanism (identical to those shown in Fig. 4) and by the cloud-processing mechanism (a).

ter by droplet activation than by the condensation of water vapour in a subsaturated environment. As expected, the preactivation ability after cloud-processing is conserved up to higher temperatures because larger pore diameters are involved, and thereby reaches the temperature regime where ice nucleation is usually ascribed to particles of biological origin only (Murray et al., 2012). Apart from deep convective clouds (Adler et al., 2013), recycling of ice-nucleating particles was recently also taken into account to explain the maintenance of cloud ice production in Arctic mixed phase stratocumulus, however without considering pre-activation effects (Solomon et al., 2015). The potential importance of pre-activation by cloud-processing clearly stimulates further research of this mechanism with different aerosol types, with the AIDA chamber as an ideal platform to explore the processing of INPs in subsequent cloud formation cycles.

\section{Summary}

Understanding the microphysical processes that lead to the formation of ice particles in the Earth's atmosphere is of vital importance for the reliable simulation of clouds in modern weather and climate models. Much effort has recently been made to identify new aerosol types contributing to the atmospheric abundance of ice-nucleating particles, e.g. biological materials like cellulose, bacteria, and marine diatoms. In this work, we have addressed a less investigated subject, namely the enhancement of the ice nucleation ability of wellknown and abundant ice-nucleating particles like dust grains due to pre-activation. Temporary exposure to a low temperature $(228 \mathrm{~K})$ provokes that pores and surface cracks of the particles are filled with ice, which makes them better nuclei for the growth of macroscopic ice crystals at high temperatures $(245-260 \mathrm{~K})$. This can in particular be important for the precipitation initiation in mixed-phase clouds because it potentially contributes to enhance the abundance of INPs at 
temperatures up to about $260 \mathrm{~K}$. Above $260 \mathrm{~K}$, the ice in the pores melts and the pre-activation of the aerosol particles by the PCF mechanism (intermediate cooling to $228 \mathrm{~K}$, $\mathrm{RH}_{\text {ice }}<100 \%$ ) is lost.

The pre-activation mechanism involves two steps: (i) the capillary condensation of supercooled water, and (ii) the subsequent homogeneous freezing of the capillary-held water. Pre-activation does not require that the aerosol particles are previously involved in an ice nucleation event. Once preactivated, the ice kept in the pores can trigger ice formation just above ice saturation without requiring any distinct nucleation threshold or particular nucleation site. We showed that aerosol particles generated from powder samples of the clay mineral illite, diatomaceous earth, and zeolite could be pre-activated in this manner, whereas the majority of particles generated from natural dust and volcanic ash samples did not yield a measurable pre-activation. Model calculations suggest that the pre-activation ability by the PCF mechanism (intermediate cooling to $228 \mathrm{~K}, \mathrm{RH}_{\mathrm{ice}}<100 \%$ ) is linked to pores of a certain dimension with diameters from about 5 to $8 \mathrm{~nm}$. Our exploratory study stimulates further research to elaborate the quantitative impact of pre-activation on primary ice formation in tropospheric clouds, including further laboratory experiments, in situ observations, and cloud modelling. 

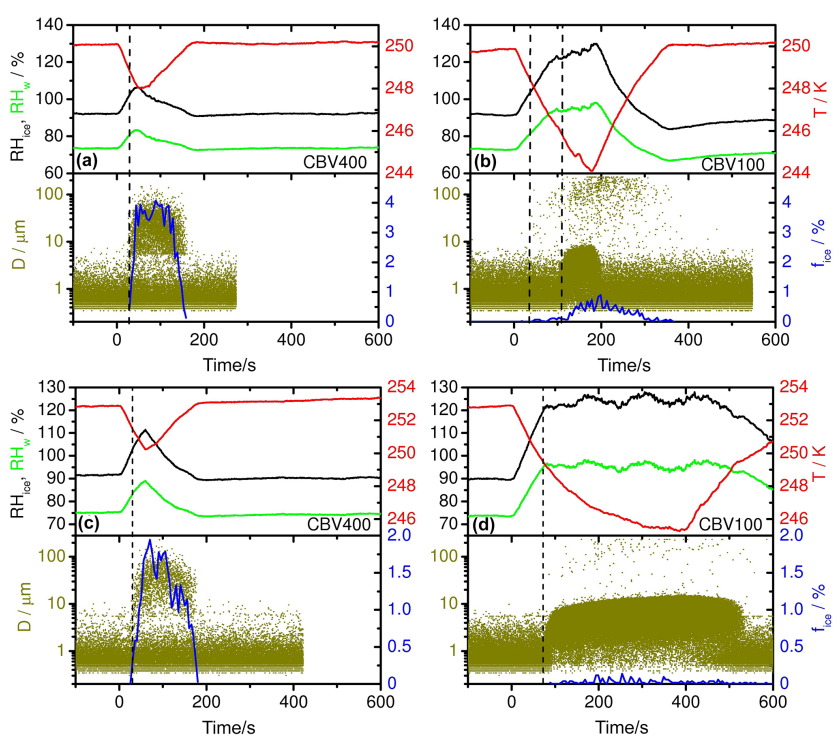

Figure A1. Comparison of the ice nucleation characteristics of preactivated CBV400 and CBV100 particles during expansion cooling started at $250 \mathrm{~K}(\mathbf{a}, \mathbf{b})$ and $253 \mathrm{~K}(\mathbf{c}, \mathbf{d})$. The data types are the same as shown in Fig. 3.

\section{Appendix A: Ice nucleation experiments with CBV100}

Figure A1 compares the measurement data from the preactivation experiments with CBV100 to those with CBV400, demonstrating the profoundly reduced pre-activation ability of the microporous zeolite material. Parts (a) and (b) show the expansion cooling runs started at $250 \mathrm{~K}$ after temporarily cooling the CBV400 and CBV100 particles to $228 \mathrm{~K}$. Whereas the pre-activated CBV400 particles give rise to a pronounced depositional ice growth mode (part (a), same data as in Fig. 3c, $f_{\text {ice }}=3.7 \%$ ), the CBV100 particles are barely ice-active $\left(f_{\text {ice }}=0.08\right)$ in the regime between $\mathrm{RH}_{\text {ice }}=100 \%$ (first vertical line) and $\mathrm{RH}_{\mathrm{w}}=100 \%$ (second vertical line). Only after the droplet activation of the CBV100 particles are significantly more ice crystals observed with $f_{\text {ice }}=0.6 \%$. This is another example for what we called the condensational ice growth mode after pre-activation, because ice formation at this temperature was only observed after temperature cycling but not for the unprocessed zeolite particles. After further warming the AIDA chamber to $253 \mathrm{~K}$, the CBV400 particles retain a high activity in the depositional ice growth mode with $f_{\text {ice }}=1.7 \%$ (Fig. A1, part c), whereas the improved ice nucleation ability of the CBV100 particles almost disappeared (part d).

\section{Appendix B: Ice nucleation experiments with illite NX}

In comparison with the zeolite particles, illite NX has a much higher intrinsic heterogeneous ice nucleation ability above $237 \mathrm{~K}$ (Hiranuma et al., 2015). It is therefore crucial
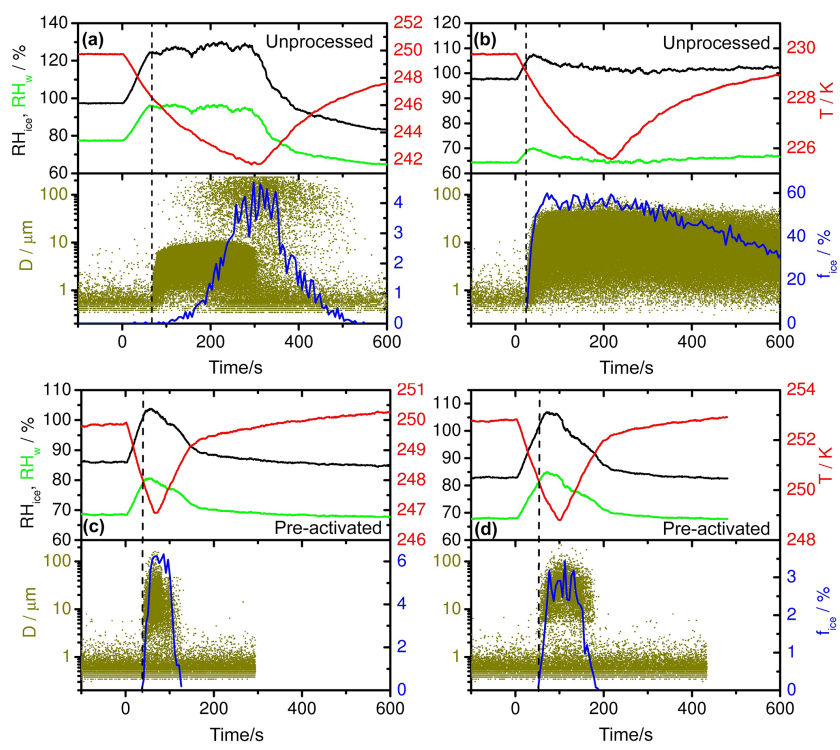

Figure B1. Ice nucleation characteristics of unprocessed $(\mathbf{a}, \mathbf{b})$ and pre-activated (c, d) illite NX particles during expansion cooling. The data types are the same as shown in Fig. 3.

to select an appropriate temperature where ice nucleation due to pre-activation can be clearly separated from the intrinsic ice nucleation behaviour. When probing the unprocessed illite NX particles in an expansion cooling experiment at $250 \mathrm{~K}$ (Fig. B1, part a), ice formation is solely due to immersion freezing after exceeding water saturation (vertical line). The ice-active fraction is below $1 \%$ for temperatures above $243 \mathrm{~K}$, but then rapidly increases to $4 \%$ within a further Kelvin of cooling. Due to the absence of ice formation below water saturation, i.e. before water droplet formation, a temperature of $250 \mathrm{~K}$ is suitable to probe the preactivation ability of the illite NX particles in the depositional ice growth mode after temperature cycling. Similar to CBV400 (Fig. 3b), the unprocessed illite NX particles show massive ice formation with $f_{\text {ice }}=58 \%$ at very low ice supersaturation values when probed at $T<237 \mathrm{~K}$ (Fig. B1, part b).

Two examples of the improved ice nucleation ability of the illite NX particles after temperature cycling are shown in parts (c) and (d) of Fig. B1. When probed at $250 \mathrm{~K}$ (part c), the pre-activated illite NX particles provoke a strong depositional ice growth mode that forms at $\mathrm{RH}_{\text {ice }}<105 \%$, in obvious contrast to the particles' intrinsic heterogeneous ice nucleation ability shown in part (a) where ice was only formed via the immersion freezing mode after droplet activation. As for CBV400, the ice-active fraction of the pre-activated aerosol particles decreases by about $50 \%$ after warming the AIDA chamber from 250 to $253 \mathrm{~K}$ (part d). 

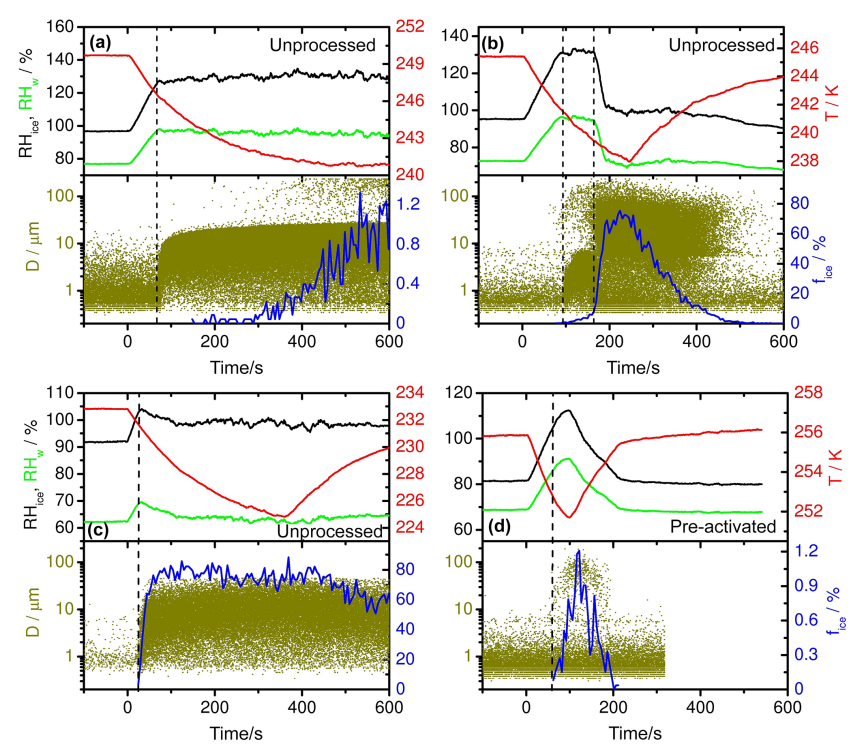

Figure C1. Ice nucleation characteristics of unprocessed $(\mathbf{a}, \mathbf{b}, \mathbf{c})$ and pre-activated (d) diatomaceous earth particles during expansion cooling. The data types are the same as shown in Fig. 3.

\section{Appendix C: Ice nucleation experiments with diatomaceous earth}

The intrinsic heterogeneous ice nucleation ability of the diatomaceous earth particles was probed at three different temperatures (parts a-c of Fig. C1). The data from parts (a) and (c) underline the transition from poor ice nucleation ability at $T>237 \mathrm{~K}$ to extraordinarily high ice nucleation ability at $T<237 \mathrm{~K}$. The unprocessed diatomaceous earth particles do not promote ice formation in the deposition mode in an expansion run started at $250 \mathrm{~K}$ (part a), and even after droplet activation (vertical line) the number concentration of ice crystals formed by immersion freezing is initially very small. Only upon further cooling to $241 \mathrm{~K}$ does the iceactive fraction gradually increase to about $1 \%$. In contrast, $80 \%$ of the aerosol population is activated at a peak $\mathrm{RH}_{\text {ice }}$ value of only $104 \%$ when the expansion run is started at $233 \mathrm{~K}$ (part c). A peculiarity of the ice nucleation behaviour of the diatomaceous earth particles is shown in part (b) of Fig. C1. Here, the intrinsic immersion freezing ability was probed at a slightly lower temperature than in the expansion run shown in part (a). Droplet activation of the aerosol particles during expansion cooling occurs at a temperature of about $241 \mathrm{~K}$ (first vertical line), and upon further cooling to $239.5 \mathrm{~K}$ (second vertical line) the ice-active fraction of the immersed aerosol particles gradually increases to about $6 \%$. Thereafter, the droplet cloud completely glaciates within a short time period of only $20 \mathrm{~s}$ although the gas temperature was still about $2.5 \mathrm{~K}$ above the homogeneous freezing temperature. This indicates that the diatomaceous earth material features some ubiquitous surface properties that induce the
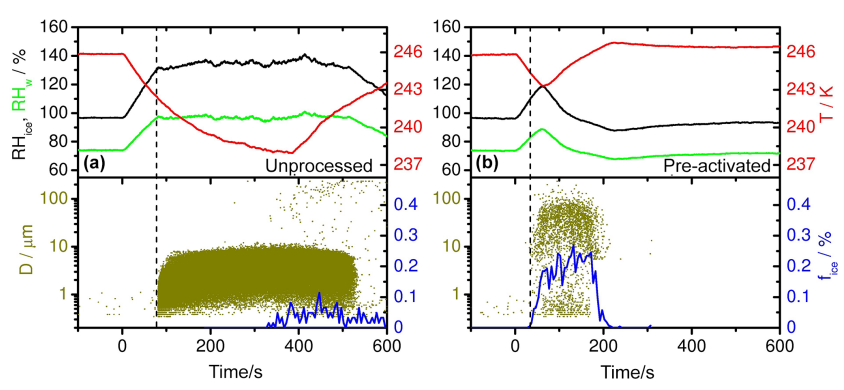

Figure D1. Ice nucleation characteristics of unprocessed (a) and pre-activated (b) GSG soot particles during expansion cooling. The data types are the same as shown in Fig. 3.

freezing of supercooled water at a temperature higher than the homogeneous freezing threshold. A higher freezing temperature means that larger pores can be filled with ice by the PCF mechanism during temperature cycling (Fig. 5), as a result of which the pre-activation ability is retained to higher temperatures. An example of the ice nucleation ability of the pre-activated diatomaceous earth particles is given in part (d) of Fig. C1, showing that even at $256 \mathrm{~K}$ a dominant depositional ice growth mode with $f_{\text {ice }}=1 \%$ can still be observed. Note that such behaviour could in principle also be expected for the illite NX particles due to their pronounced intrinsic heterogeneous ice nucleation ability above $237 \mathrm{~K}$. The measurement data, however, reveal that the decrease of $f_{\text {ice }}$ with increasing temperature is faster for illite NX compared to diatomaceous earth (Fig. 4). This might be due to the overall lack of larger void spaces in the clay mineral, meaning that such larger pores which could retain ice at higher temperatures are just not available.

\section{Appendix D: Ice nucleation experiments with GSG soot}

GSG soot particles are an ideal candidate to probe the preactivation efficiency because they are intrinsically even less ice-active than the CBV400 particles at $T>237 \mathrm{~K}$. The expansion run with freshly injected GSG particles started at 246 K (part a of Fig. D1) discloses the absence of any ice formation in the deposition mode, and after droplet activation (first vertical line) only a minor nucleation mode due to immersion freezing with $f_{\text {ice }}=0.05 \%$ can be observed after the gas temperature has dropped below $239 \mathrm{~K}$. As shown by previous AIDA measurements, however, the GSG soot particles are very efficient deposition mode INPs below $237 \mathrm{~K}$ (Möhler et al., 2005), suggesting that the PCF mechanism becomes active for this kind of material as well. This is supported by our new experiments, showing that pre-activated GSG soot particles reveal a clear depositional ice growth mode when probed at $246 \mathrm{~K}$ after temporary cooling to $228 \mathrm{~K}$ (part (b) of Fig. D1). The ice-active fraction is rather small with only about $0.2 \%$, and the pre-activation ability already disappears completely at temperatures above $250 \mathrm{~K}$. This in- 

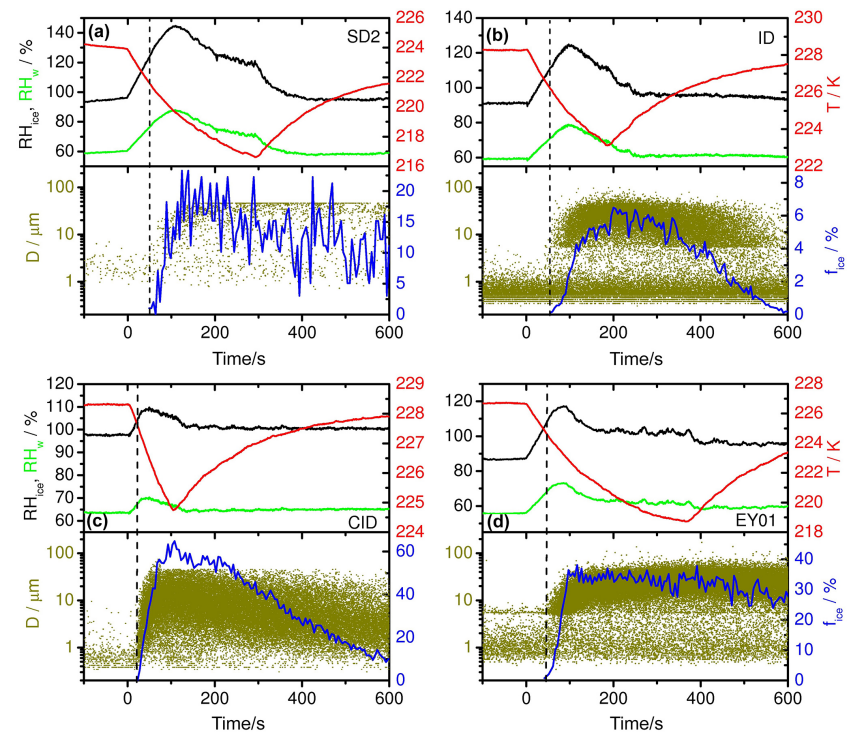

Figure E1. Comparison of the ice nucleation characteristics of unprocessed SD2 (a), ID (b), CID (c), and EY01 (d) particles during expansion cooling at temperatures below $237 \mathrm{~K}$. The data types are the same as shown in Fig. 3. In the experiment with the SD2 particles, only the optical particle counter with the upper size threshold of $46 \mu \mathrm{m}$ was operated. This means that larger ice crystals were still appropriately counted but not correctly sized (i.e. classified to the size channel $46 \mu \mathrm{m})$.

dicates that the void spaces in the soot aggregates are rather small so that the enclosed ice pockets have a low melting temperature. As already highlighted, the pre-activation ability shown in part (b) is only observed when a fresh load of GSG soot particles is subjected to the temperature-cycling programme. When the cloud-processed and thereby compacted particles from the experiment shown in part (a) are temporarily cooled to $228 \mathrm{~K}$, their ice nucleation ability does not improve at $246 \mathrm{~K}$.

\section{Appendix E: Ice nucleation experiments with SD2, ID, CID, and EY01}

As emphasised in the discussion, pre-activation by the PCF mechanism at $\mathrm{RH}_{\text {ice }}<100 \%$ requires the formation of icefilled pores during the temporary cooling cycle to $228 \mathrm{~K}$. These ice-filled pores facilitate the depositional growth of macroscopic ice crystals after warming the pre-activated aerosol particles to temperatures in the range from 245 to $260 \mathrm{~K}$ where the pre-activation ability was tested in succeeding expansion cooling experiments. The pronounced intrinsic heterogeneous ice nucleation ability at very low supersaturation thresholds of the zeolite CBV400, illite NX, and diatomaceous earth particles at $T<237 \mathrm{~K}$ can also be explained by the PCF mechanism. This observation indicates that the pores of the materials were already filled with ice

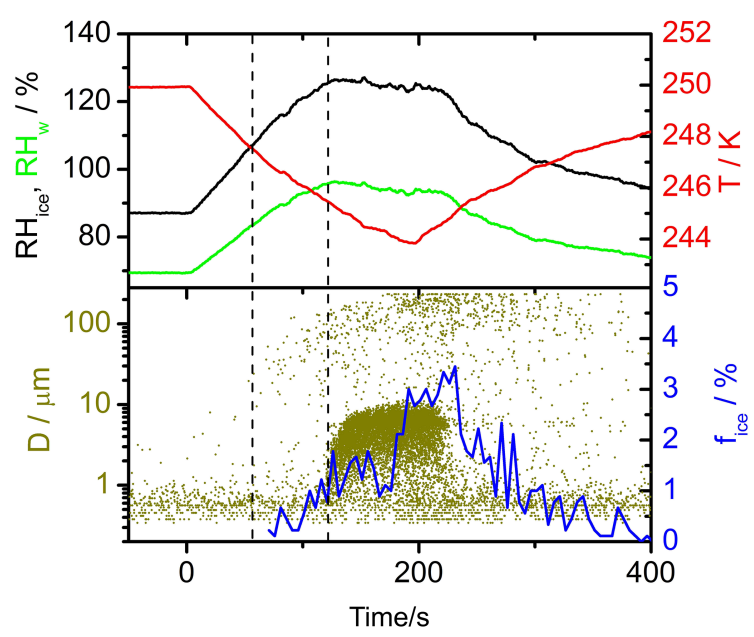

Figure E2. Ice nucleation characteristics of pre-activated CID particles during expansion cooling. The data types are the same as shown in Fig. 3.

before the start of the expansion cooling experiments, underlining the availability of pores in a size regime where water condensation can occur at relative humidities below ice saturation. Since the latter is the prerequisite for observing pre-activation at $\mathrm{RH}_{\text {ice }}<100 \%$, we can use the intrinsic heterogeneous ice nucleation ability of a certain compound at $T<237 \mathrm{~K}$ as a proxy to estimate whether it is prone to preactivation or not.

In Fig. E1, we have compiled AIDA data for the intrinsic heterogeneous ice nucleation abilities of the SD2, ID, CID, and EY01 particles probed in expansion cooling experiments at $T<237 \mathrm{~K}$. The experiments with the ID and CID particles were conducted in the present study, whereas the data for SD2 and EY01 were taken from preceding measurement campaigns (Möhler et al., 2006; Steinke et al., 2011). The SD2, ID, and EY01 particles promote heterogeneous ice nucleation below water saturation, but the $\mathrm{RH}_{\text {ice }}$ threshold for the initiation of ice formation is in the range between 110 and $120 \%$, which is clearly higher than for the CBV400, illite $\mathrm{NX}$, and diatomaceous earth particles. Consequently, these samples were found not to be susceptive to pre-activation at $\mathrm{RH}_{\mathrm{ice}}<100 \%$, so that temperature cycling did not modify their intrinsic heterogeneous ice nucleation ability at temperatures between 245 and $260 \mathrm{~K}$. In contrast, a small preactivation mode due to depositional ice growth was observed for the CID particles (Fig. E2). Unprocessed CID particles were shown to be ice-active only in the immersion freezing mode for temperatures above $240 \mathrm{~K}$ (Kanji et al., 2011). After temperature cycling, however, macroscopic ice growth starts at $\mathrm{RH}_{\text {ice }}=105 \%$ (first vertical line in Fig. E2) when the particles are probed in an expansion cooling experiment at $250 \mathrm{~K}$. In the later course of expansion cooling (second vertical line), the CID particles are activated to cloud droplets and additional ice crystals are formed due to the intrinsic im- 
mersion freezing ability of the material. The observation that the CID particles are prone to pre-activation manifests itself in their higher intrinsic heterogeneous ice nucleation ability at $T<237 \mathrm{~K}$ compared to SD2, ID, and EY01 (part c in Fig. E1). Ice formation initiates at $\mathrm{RH}_{\mathrm{ice}}=103 \%$ and $60 \%$ of the aerosol population gets activated although the peak relative humidity with respect to ice is limited to $108 \%$ during expansion cooling. Ice nucleation measurements for CID performed with a continuous flow diffusion chamber show much higher onset ice relative humidities at temperatures below $237 \mathrm{~K}$ compared to the AIDA where the dust particles are probed in situ after a longer residence time in a cold and humid environment (Koehler et al., 2010). This finding stimulates further research on the kinetics of the PCF mechanism because it could be important for the interpretation of ice nucleation efficiencies measured by INP counters at $T<237 \mathrm{~K}$.

Acknowledgements. Continuous support by all members of the Engineering and Infrastructure group of IMK-AAF, in particular by Olga Dombrowski, Rainer Buschbacher, Tomasz Chudy, Steffen Vogt, and Georg Scheurig, is gratefully acknowledged. This work has been funded by the Helmholtz-Gemeinschaft Deutscher Forschungszentren as part of the programme "Atmosphere and Climate" and by the Deutsche Forschungsgemeinschaft (DFG) as part of the Ice Nuclei Research Unit INUIT (FOR 1525, project MO 668/4-2).

The article processing charges for this open-access publication were covered by a Research

Centre of the Helmholtz Association.

Edited by: R. Krejci

\section{References}

Adler, G., Koop, T., Haspel, C., Taraniuk, I., Moise, T., Koren, I., Heiblum, R. H., and Rudich, Y.: Formation of highly porous aerosol particles by atmospheric freeze-drying in ice clouds, $\mathrm{P}$. Natl. Acad. Sci. USA, 110, 20414-20419, 2013.

Alexander, J. M., Meland, B., Laskina, O., Young, M. A., Grassian, V. H., and Kleiber, P. D.: Light scattering from diatomaceous earth aerosol, J. Quant. Spectrosc. Ra., 125, 33-37, 2013.

Aylmore, L. A. G. and Quirk, J. P.: Micropore Size Distributions of Clay Mineral Systems, J. Soil Sci., 18, 1-17, 1967.

Boucher, O., Randall, D., Artaxo, P., Bretherton, C., Feingold, G., Forster, P., Kerminen, V. M., Kondo, Y., Liao, H., Lohmann, U., Rasch, P., Satheesh, S. K., Stevens, B., and Zhang, X. Y.: Clouds and Aerosols, in: Climate Change 2013: The Physical Science Basis. Contribution of Working Group I to the Fifth Assessment Report of the Intergovernmental Panel on Climate Change, edited by: Stocker, T. F., Qin, D., Plattner, G.-K., Tignor, M., Allen, S. K., Boschung, J., Nauels, A., Xia, Y., Bex, V., and Midgley, P. M.: Cambridge University Press, Cambridge, United Kingdom and New York, NY, USA, 2013.

DeCarlo, P. F., Slowik, J. G., Worsnop, D. R., Davidovits, P., and Jimenez, J. L.: Particle morphology and density characterization by combined mobility and aerodynamic diameter measurements. Part 1: Theory, Aerosol. Sci. Tech., 38, 1185-1205, 2004.

DeMott, P. J., Möhler, O., Stetzer, O., Vali, G., Levin, Z., Petters, M. D., Murakami, M., Leisner, T., Bundke, U., Klein, H., Kanji, Z. A., Cotton, R., Jones, H., Benz, S., Brinkmann, M., Rzesanke, D., Saathoff, H., Nicolet, M., Saito, A., Nillius, B., Bingemer, H., Abbatt, J., Ardon, K., Ganor, E., Georgakopoulos, D. G., and Saunders, C.: Resurgence in Ice Nuclei Measurement Research, B. Am. Meteorol. Soc., 92, 1623-1635, 2011.

Fahey, D. W., Gao, R.-S., Möhler, O., Saathoff, H., Schiller, C., Ebert, V., Krämer, M., Peter, T., Amarouche, N., Avallone, L. M., Bauer, R., Bozóki, Z., Christensen, L. E., Davis, S. M., Durry, G., Dyroff, C., Herman, R. L., Hunsmann, S., Khaykin, S. M., Mackrodt, P., Meyer, J., Smith, J. B., Spelten, N., Troy, R. F., Vömel, H., Wagner, S., and Wienhold, F. G.: The AquaVIT-1 intercomparison of atmospheric water vapor measurement techniques, Atmos. Meas. Tech., 7, 3177-3213, doi:10.5194/amt-7-3177-2014, 2014.

Fukuta, N.: Activation of Atmospheric Particles as Ice Nuclei in Cold and Dry Air, J. Atmos. Sci., 23, 741-750, 1966.

Higuchi, K. and Fukuta, N.: Ice in Capillaries of Solid Particles and Its Effect on Their Nucleating Ability, J. Atmos. Sci., 23, 187190, 1966.

Hinds, W. C.: Aerosol Technology, John Wiley \& Sons, Inc., New York, 1999.

Hiranuma, N., Augustin-Bauditz, S., Bingemer, H., Budke, C., Curtius, J., Danielczok, A., Diehl, K., Dreischmeier, K., Ebert, M., Frank, F., Hoffmann, N., Kandler, K., Kiselev, A., Koop, T., Leisner, T., Möhler, O., Nillius, B., Peckhaus, A., Rose, D., Weinbruch, S., Wex, H., Boose, Y., DeMott, P. J., Hader, J. D., Hill, T. C. J., Kanji, Z. A., Kulkarni, G., Levin, E. J. T., McCluskey, C. S., Murakami, M., Murray, B. J., Niedermeier, D., Petters, M. D., O’Sullivan, D., Saito, A., Schill, G. P., Tajiri, T., Tolbert, M. A., Welti, A., Whale, T. F., Wright, T. P., and Yamashita, K.: A comprehensive laboratory study on the immersion freezing behavior of illite NX particles: a comparison of 17 ice nucleation measurement techniques, Atmos. Chem. Phys., 15, 2489-2518, doi:10.5194/acp-15-2489-2015, 2015.

Hoose, C. and Möhler, O.: Heterogeneous ice nucleation on atmospheric aerosols: a review of results from laboratory experiments, Atmos. Chem. Phys., 12, 9817-9854, doi:10.5194/acp-12-98172012, 2012.

Janczuk, B. and Bialopiotrowicz, T., Components of Surface FreeEnergy of Some Clay-Minerals, Clay Clay Miner., 36, 243-248, 1988.

Janssen, A. H., Koster, A. J., and de Jong, K. P.: On the shape of the mesopores in zeolite Y: A three-dimensional transmission electron microscopy study combined with texture analysis, J. Phys. Chem. B, 106, 11905-11909, 2002.

Janssen, A. H., Talsma, H., van Steenbergen, M. J., and de Jong, K. P.: Homogeneous nucleation of water in mesoporous zeolite cavities, Langmuir, 20, 41-45, 2004.

Kanji, Z. A., DeMott, P. J., Möhler, O., and Abbatt, J. P. D.: Results from the University of Toronto continuous flow diffusion chamber at ICIS 2007: instrument intercomparison and ice onsets for different aerosol types, Atmos. Chem. Phys., 11, 31-41, doi:10.5194/acp-11-31-2011, 2011. 
Knopf, D. A. and Koop, T.: Heterogeneous nucleation of ice on surrogates of mineral dust, J. Geophys. Res.-Atmos., 111, D12201, doi:10.1029/2005JD006894, 2006.

Koehler, K. A., Kreidenweis, S. M., DeMott, P. J., Petters, M. D., Prenni, A. J., and Möhler, O.: Laboratory investigations of the impact of mineral dust aerosol on cold cloud formation, Atmos. Chem. Phys., 10, 11955-11968, doi:10.5194/acp10-11955-2010, 2010.

Korunic, Z.: Diatomaceous earths, a group of natural insecticides, J. Stored Prod. Res., 34, 87-97, 1998.

Kovács, T., Meldrum, F. C., and Christenson, H. K.: Crystal Nucleation without Supersaturation, J. Phys. Chem. Lett., 3, 16021606, 2012.

Linke, C., Möhler, O., Veres, A., Mohácsi, Á., Bozóki, Z., Szabó, G., and Schnaiter, M.: Optical properties and mineralogical composition of different Saharan mineral dust samples: a laboratory study, Atmos. Chem. Phys., 6, 3315-3323, doi:10.5194/acp-63315-2006, 2006.

Ma, X. F., Zangmeister, C. D., Gigault, J., Mulholland, G. W., and Zachariah, M. R.: Soot aggregate restructuring during water processing, J. Aerosol Sci., 66, 209-219, 2013.

Marcolli, C.: Deposition nucleation viewed as homogeneous or immersion freezing in pores and cavities, Atmos. Chem. Phys., 14, 2071-2104, doi:10.5194/acp-14-2071-2014, 2014.

Möhler, O., Stetzer, O., Schaefers, S., Linke, C., Schnaiter, M., Tiede, R., Saathoff, H., Krämer, M., Mangold, A., Budz, P., Zink, P., Schreiner, J., Mauersberger, K., Haag, W., Kärcher, B., and Schurath, U.: Experimental investigation of homogeneous freezing of sulphuric acid particles in the aerosol chamber AIDA, Atmos. Chem. Phys., 3, 211-223, doi:10.5194/acp-3-211-2003, 2003.

Möhler, O., Büttner, S., Linke, C., Schnaiter, M., Saathoff, H., Stetzer, O., Wagner, R., Krämer, M., Mangold, A., Ebert, V., and Schurath, U.: Effect of Sulphuric Acid Coating on Heterogeneous Ice Nucleation by Soot Aerosol Particles, J. Geophys. Res.-Atmos., 110, D11210, doi:10.1029/2004JD005169, 2005.

Möhler, O., Field, P. R., Connolly, P., Benz, S., Saathoff, H., Schnaiter, M., Wagner, R., Cotton, R., Krämer, M., Mangold, A., and Heymsfield, A. J.: Efficiency of the deposition mode ice nucleation on mineral dust particles, Atmos. Chem. Phys., 6, 30073021, doi:10.5194/acp-6-3007-2006, 2006.

Mossop, S. C.: Sublimation Nuclei, P. Phys. Soc. Lond. B, 69, 161164, 1956

Murphy, D. M. and Koop, T.: Review of the vapour pressures of ice and supercooled water for atmospheric applications, Q. J. Roy. Meteor. Soc., 131, 1539-1565, 2005.

Murray, B. J., O'Sullivan, D., Atkinson, J. D., and Webb, M. E.: Ice nucleation by particles immersed in supercooled cloud droplets, Chem. Soc. Rev., 41, 6519-6554., 2012.

Persiantseva, N. M., Popovicheva, O. B., and Shonija, N. K.: Wetting and hydration of insoluble soot particles in the upper troposphere, J. Environ. Monit., 6, 939-945, 2004.

Prenni, A. J., Petters, M. D., Kreidenweis, S. M., Heald, C. L., Martin, S. T., Artaxo, P., Garland, R. M., Wollny, A. G., and Poschl, U.: Relative roles of biogenic emissions and Saharan dust as ice nuclei in the Amazon basin, Nat. Geosci., 2, 402-405, 2009.
Pruppacher, H. R. and Klett, J. D.: Microphysics of Clouds and Precipitation, Kluwer Acacdemic Publishers, Dordrecht, 1997.

Rao, N. P. and McMurry, P. H.: Effect of the Tolman SurfaceTension Correction on Nucleation in Chemically Reacting Systems, Aerosol. Sci. Tech., 13, 183-195, 1990.

Roberts, P. and Hallett, J., A Laboratory Study of Ice Nucleating Properties of Some Mineral Particulates, Q. J. Roy. Meteor. Soc., 94, 25-34, 1968.

Sjogren, S., Gysel, M., Weingartner, E., Baltensperger, U., Cubison, M. J., Coe, H., Zardini, A. A., Marcolli, C., Krieger, U. K., and Peter, T.: Hygroscopic growth and water uptake kinetics of twophase aerosol particles consisting of ammonium sulfate, adipic and humic acid mixtures, J. Aerosol Sci., 38, 157-171, 2007.

Solomon, A., Feingold, G., and Shupe, M. D.: The role of ice nuclei recycling in the maintenance of cloud ice in Arctic mixedphase stratocumulus, Atmos. Chem. Phys., 15, 10631-10643, doi:10.5194/acp-15-10631-2015, 2015.

Steinke, I., Möhler, O., Kiselev, A., Niemand, M., Saathoff, H., Schnaiter, M., Skrotzki, J., Hoose, C., and Leisner, T.: Ice nucleation properties of fine ash particles from the Eyjafjallajökull eruption in April 2010, Atmos. Chem. Phys., 11, 12945-12958, doi:10.5194/acp-11-12945-2011, 2011.

Todd, M. C., Washington, R., Martins, J. V., Dubovik, O., Lizcano, G., M'Bainayel, S., and Engelstaedter, S.: Mineral dust emission from the Bodélé Depression, northern Chad, during BoDEx 2005, J. Geophys. Res.-Atmos., 112, D06207, doi:10.1029/2006JD007170, 2007.

Vali, G.: Repeatability and randomness in heterogeneous freezing nucleation, Atmos. Chem. Phys., 8, 5017-5031, doi:10.5194/acp-8-5017-2008, 2008.

Vali, G., DeMott, P. J., Möhler, O., and Whale, T. F.: Technical Note: A proposal for ice nucleation terminology, Atmos. Chem. Phys., 15, 10263-10270, doi:10.5194/acp-15-10263-2015, 2015.

Wagner, R., Bunz, H., Linke, C., Möhler, O., Naumann, K. H., Saathoff, H., Schnaiter, M., and Schurath, U., Chamber Simulations of Cloud Chemistry: The AIDA Chamber, in: Proceedings of the NATO Advances Research Workshop on Environmental Simulation Chambers: Application to Atmospheric Chemical Processes, held in Zakopane, Poland, from 1 to 4 October 2004, edited by: Barnes, I. and Rudzinski, K. J., Springer, 2006.

Wagner, R., Möhler, O., Saathoff, H., and Schnaiter, M.: Enhanced high-temperature ice nucleation ability of crystallized aerosol particles after preactivation at low temperature, J. Geophys. Res.Atmos., 119, 8212-8230, 2014.

Zobrist, B., Marcolli, C., Koop, T., Luo, B. P., Murphy, D. M., Lohmann, U., Zardini, A. A., Krieger, U. K., Corti, T., Cziczo, D. J., Fueglistaler, S., Hudson, P. K., Thomson, D. S., and Peter, T.: Oxalic acid as a heterogeneous ice nucleus in the upper troposphere and its indirect aerosol effect, Atmos. Chem. Phys., 6, 3115-3129, doi:10.5194/acp-6-3115-2006, 2006.

Zobrist, B., Koop, T., Luo, B. P., Marcolli, C., and Peter, T.: Heterogeneous ice nucleation rate coefficient of water droplets coated by a nonadecanol monolayer, J. Phys. Chem. C, 111, 2149-2155, 2007. 